\title{
Immunomodulatory properties of triterpenes
}

\author{
Gülin Renda • İçim Gökkaya • Didem Şöhretoğlu
}

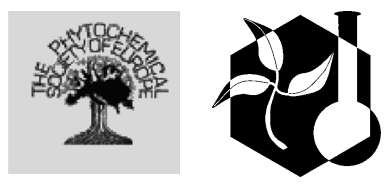

Received: 12 July 2021 / Accepted: 19 October 2021/Published online: 18 November 2021

(C) The Author(s), under exclusive licence to Springer Nature B.V. 2021

\begin{abstract}
The immune system is one of the main defence mechanisms of the human body. Inadequacy of this system or immunodeficiency results in increased risk of infections and tumours, whereas over-activation of the immune system causes allergic or autoimmune disorders. A well-balanced immune system is important for protection and for alleviation of these diseases. There is a growing interest to maintain a well-balanced immune system, especially after the Covid-19 pandemic. Many biological extracts, as well as natural products, have become popular due to their wide array of immunomodulatory effects and influence on the immune system. Triterpenes, one of the secondary metabolite groups of medicinal plants, exhibit immunomodulatory properties by various mechanisms. Different triterpenes, including components of commonly consumed plants, can promote some protection and alleviation of disease symptoms linked with immune responses and thus enhance overall well-being. This review aims to highlight the efficacy of triterpenes in light of the available literature evidence regarding the immunomodulatory properties of triterpenes. We have
\end{abstract}

G. Renda · İ. Gökkaya

Department of Pharmacognosy, Faculty of Pharmacy,

Karadeniz Technical University, 61100 Trabzon, Turkey

D. Şöhretoğlu (

Department of Pharmacognosy, Faculty of Pharmacy,

Hacettepe University, 06100 Sihhiye, Ankara, Turkey

e-mail: didems@hacettepe.edu.tr reviewed widely investigated immunomodulatory triterpenes; oleanolic acid, glycyrrhizin, glycyrrhetinic acid, pristimerin, ursolic acid, boswellic acid, celastrol, lupeol, betulin, betulinic acid, ganoderic acid, cucumarioside, and astragalosides which have important immunoregulatory properties. In spite of many preclinical and clinical trials were conducted on triterpenes related to their immunoregulatory actions, current studies have several limitations. Therefore, especially more clinical studies with optimal design is essential.

Keywords Terpenoids - Natural product . Immunostimulation - Immunosuppression · Immunoregulation

$\begin{array}{ll}\text { Abbreviations } \\ \text { CD } & \text { Cluster of differentiation } \\ \text { Con A } & \text { Concanavalin A } \\ \text { COX } & \text { Cyclooxygenase } \\ \text { DCs } & \text { Dendric cells } \\ \text { ERK } & \text { Extracellular signal-regulated kinases } \\ \text { HMGB1 } & \text { High mobility group box 1 protein } \\ \text { IFN } & \text { İNterferon } \\ \text { Ig } & \text { Immunoglobulin } \\ \text { IL } & \text { Interleukin } \\ \text { iNOS } & \text { İNducible nitric oxide synthase } \\ \text { JNK } & \text { C-Jun N-terminal kinases } \\ \text { LPS } & \text { Lipopolysacharides } \\ \text { MAPK } & \text { Mitogen-activated protein kinase }\end{array}$




$\begin{array}{ll}\text { MCP-1 } & \text { Monocyte chemoattractant protein 1 } \\ \text { MMP } & \text { Matrix metalloproteinase } \\ \text { NF- } \mathrm{B} & \begin{array}{l}\text { Nuclear factor kappa-light-chain-enhancer } \\ \text { of activated B cells }\end{array} \\ \text { NK } & \text { Natural killer } \\ \text { Nrf2 } & \text { Nuclear factor erythroid 2-related factor } \\ \text { PBMC } & \text { Peripheral blood mononuclear cells } \\ \text { PGE } & \text { Prostoglandin E } \\ \text { PLA2 } & \text { Phospholipase A2 } \\ \text { ROR } \gamma \text { t } & \text { RAR-related orphan receptor gamma } \\ \text { SOCS3 } & \text { Suppressor of Cytokine Signaling 3 } \\ \text { STAT } & \text { Signal transducer and activator of } \\ & \text { transcription } \\ \text { Th } & \text { T helper } \\ \text { TLR } & \text { Toll like receptor } \\ \text { TNF } & \text { Tumor necrosis factor }\end{array}$

\section{Introduction}

The immune system comprises two lines of defense, i.e. innate immunity and adaptive immunity. Natural killer cells (NK), complement systems, macrophages, antigen-presenting cells, and neutrophils are parts of the innate immune system. These cells produce a nonspecific response when encountering antigens. Mature $\mathrm{T}$ and $\mathrm{B}$ lymphocytes responsible for adaptive immunity carry surface molecules called Clusters of Differentiation (CD). These molecules functionally define different $\mathrm{T}$-cell subsets, namely $\mathrm{CD} 4^{+} \mathrm{T}$ helper cells (Th) and $\mathrm{CD}^{+} \mathrm{T}$ cytotoxic cells. Th cells have different subpopulations, including Th1, Th2, Th17, and Treg (McComb et al. 2019; Songu and Katılmış 2012). Th1 cells, which play a role in cellular immunity, activate macrophages and destruction intracellular pathogens. Th2 cells induce immunoglobulin differentiation and antibody secretion and thus contribute to humoral immunity. The primary role of Th17 cells in immunity is the defense against infections caused by pathogens. Treg cells cause suppression of the immune system by preventing excessive $\mathrm{T}$ cell response. $\mathrm{CD} 8^{+} \mathrm{T}$ cytotoxic cells increase apoptosis in antigen-loaded cells (McComb et al. 2019).

Cytokines are cellular signaling molecules and their secretion following the activation of Th cells. Other cells that can produce cytokines include macrophages,
B lymphocytes, and mast cells. Cytokines provide intercellular communication in the immune response and stimulate the migration of cells towards sites of inflammation, infection, and trauma. Cytokines have normal physiological functions, including growth and differentiation of hematopoietic, lymphoid, and mesenchymal cells, and regulation of host defense mechanisms. Conversely, their uncontrolled or inappropriate production can lead to the formation of autoimmune and inflammatory diseases. They are divided into four groups as Th1(IL-2, IFN $\gamma, \mathrm{TNF} \alpha$ ), Th2 (IL-4, IL-5, IL-6, IL-9, and IL-13), Th17 (IL-17, IL-21, IL-22), and Treg (TGF $\beta$, IL-10, IL-35) cytokines according to the place where they are produced (Gulati et al. 2016). According to their effects, cytokines are clustered in three classes as pro-inflammatory, anti-inflammatory, and those showing both effects (Wahab and Hussain 2013; Shokryazdan et al. 2017). The main pro-inflammatory cytokines that induce inflammatory reactions are tumor necrosis factor- $\alpha$ (TNF- $\alpha$ ), interleukin-1 (IL-1), IL-12, IL-17, and IL-18. TNF- $\alpha$ stimulates the acute phase of the immune response by increasing production of chemokine ligands with a Cys-X-Cys motif (C-X-C motif) [i.e. CXCL1, CXCL2, and CXCL5] and migration of neutrophils and macrophages to the site of inflammation. IL-1, which has three forms, IL- $1 \alpha$, IL- $1 \beta$, and IL-1Ra, is produced and released in the early stages of the immune response. The effects of IL- 1 are similar to TNF- $\alpha$. IL- $1 \beta$ affects histamine release in mast cells, leading to vasodilation and localized inflammation. IL-17A/F alone are not potent inflammatory cytokines, but their effects are enhanced in the presence of other pro-inflammatory cytokines and they show potent inflammatory activity. IL-17A/F activates neutrophils and monocytes and generates an immune response against pathogens. Major anti-inflammatory cytokines are IL-1 receptor antagonist, IL-4, IL-10 and IL-13 (Shokryazdan et al. 2017). IL-4 provides Th cells to differentiate into Th2 cells. It induces the growth of differentiated Th2 cells, resulting in an antibody response (Arango Duque and Descoteaux 2014; Wahab and Hussain 2013; Songu and Katılmış 2012). Some cytokines may show anti-inflammatory or pro-inflammatory properties in different situations. These cytokines include leukemia inhibitory factor, interferon (IFN)- $\alpha$, IL-6, and transforming growth factor (TGF- $\beta$ ) An exaggerated immune reaction demonstrated by over-production of pro-inflammatory 
cytokines too quickly is known as a cytokine storm. A cytokine storm may can be life-threatening and lead to multiple organ failure (Shokryazdan et al. 2017).

The production of both protein mediators and inducible enzymes in the immune system is associated with the induction of transcription factors such as Nuclear Factor kappa B (NF- $\mathrm{B}$ ), Nuclear factor of activated T-cells, and Signal transducer and activator of transcription (STAT). Toll-like receptors (TLR)s are signal transduction membrane proteins that play an important role in the activation of NF- $\kappa \mathrm{B}$. Different adapter proteins (myeloid differentiating factor 88 (MyD88), TRIF, etc.) bind to TLRs, leading to NF- $\kappa \mathrm{B}$ activation and induction of the release of inflammatory cytokines (Kawai and Akira 2007). NF- $\mathrm{KB}$ is involved in the expression of genes encoding proinflammatory cytokines, chemokines, inducible enzymes such as cyclooxygenase (COX)-2 and inducible nitric oxide synthase (iNOS), growth factors and immune receptors, as well as adhesion molecules including intercellular cell adhesion molecule 1 (ICAM-1), vascular cell adhesion molecule 1 (VCAM-1) (Napetschnig and $\mathrm{Wu}$ 2013). The STAT protein family is another effective pathway in the regulation of immunoregulation. Different STAT proteins alter cytokines levels and various proteins including janus kinases proteins (JAK), GATA3 (a transcription factor that regulates Th2 cytokine production) and RAR-related orphan receptor gamma (ROR $\gamma \mathrm{t}-\mathrm{Th} 17$ transcription factor) involve in this process (O'Shea and Plenge 2012).

Immunomodulators which are biological or synthetic agents that have the ability to stimulate, suppress or modulate any aspect of the immune system and boost or suppress the host defense response, are classified as immunoadjuvant, immunostimulants, and immunosuppressants (Mohamed et al. 2017; Shantilal et al. 2018).

Immunostimulants are agents enhance the activity of immunsystem. Immunoadjuvants are specific immune stimulatory molecules that enhance the efficacy of vaccines or provoke tumor-specific immune responses. Immunosuppressants which are the molecules that activate or induce the mediators or components of the immune system and inhibit the immune system, can be used to control the pathological immune reaction following organ transplantation, or in the treatment of infection-associated immunopathology, hypersensitivity reactions, and autoimmune diseases. Immunomodulators are monoclonal antibodies or chemical compounds used to help regulate or normalize the immune system (Jantan et al. 2015).

Previous studies showed that natural products with immunomodulatory activity had been used in the treatment of autoimmune diseases, inflammatory disorders, and cancer. Plant secondary metabolites such as triterpenoids, flavonoids, diterpenoids, and alkaloids, as well as some polysaccharides are known to promote immunomodulatory activity, whereas others, such as curcumin, capsaicin, quercetin, resveratrol, andrographolide, epigallocathecin-3-O-gallate, colchicine, and genistein are known to exhibit significant activities in different immune pathways in vitro (Harun et al. 2020; Ríos 2010).

Triterpenes are secondary metabolites consisting of 30 carbon atoms formed by the combination of six isoprene units. As a result of the cyclization and oxidation of two $\mathrm{C}_{15}$ units, squalene, or related acyclic 30-carbon $\mathrm{C}_{30}$ precursors, different triterpenes can be formed. Based on this, triterpenes are divided into two main groups as tetracyclic (dammarane, cucurbitane, lanostane and cycloartane types) and pentacyclic triterpenes (oleanane, ursane, lupane, friedelane, hopane, and taraxastane types). Apart from these structures, there are nor triterpenoids formed in tetracyclic triterpene precursors by oxidation and degradation. Compounds in this group have less than 30 carbon atoms in their main structure. Nortriterpenoid compounds are classified into two groups as limonoids $\left(\mathrm{C}_{26}\right)$ and quassinoids $\left(\mathrm{C}_{20}\right.$ and $\left.\mathrm{C}_{19}\right)$. In preclinical studies, it was shown that triterpenes have a wide range of pharmacological effects including anticancer, antioxidant, anti-inflammatory, antiatherosclerotic, antiviral, hepatoprotective, and immunomodulatory activities (Battineni et al. 2018; Ghiulai et al. 2020) (Fig. 1).

It has been reported that the anti-oxidant, antitumor, anti-microbial, and anti-inflammatory activity mechanisms of triterpenes result from their modulation of the immune system (Harun et al. 2020; Ríos 2010). In general, there are limited review articles that compile the immunomodulatory studies of compounds with triterpene structure. The present study aims to review the immunomodulatory activities of triterpenes isolated from natural sources until today.

According to this aim, we searched international databases (Science Direct and PubMed) and academic search engines (Google Scholar) were used to access 
Fig. 1 Structures of some tetracyclic and pentacyclic triterpene skeletons

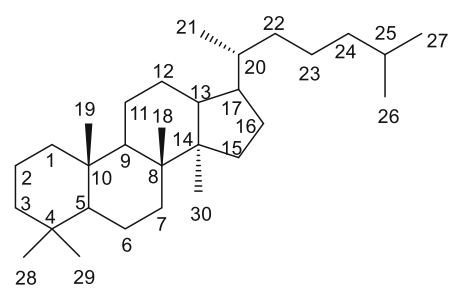

Dammarane

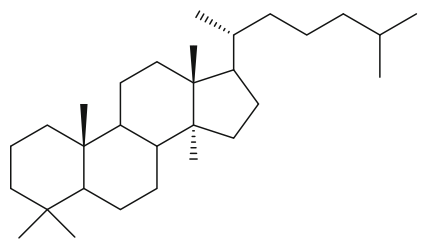

Lanostane

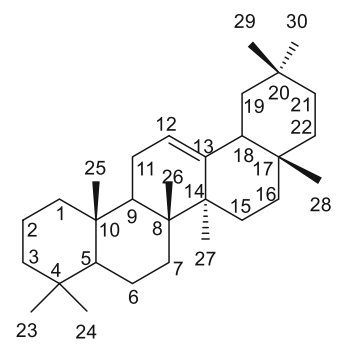

Oleanane

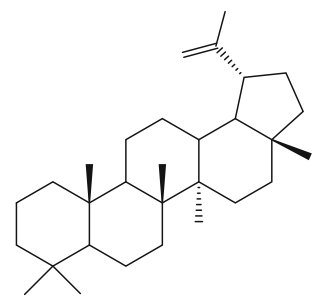

Lupane<smiles>CC(C)CCCC1CC[C@H]2C3CCC4C(C)(C)CCCC45CC35CC[C@]12C</smiles>

Cycloartane<smiles>CC1CCC2(C)CC[C@]3(C)C(CCC4C5(C)CCCC(C)(C)C5CCC43C)C2C1C</smiles>

Ursane<smiles>C=C(C)[C@H]1CC[C@@]2(C)C1CC[C@]1(C)C2CCC2[C@]1(C)CCC1C(C)(C)CCC[C@]12C</smiles>

Hopane

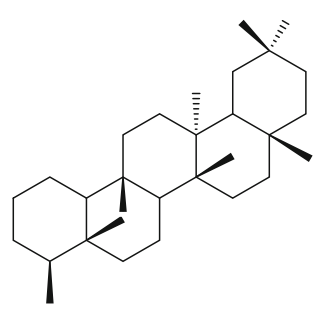

Friedelane<smiles>C[C@H]1CC[C@]2(C)CC[C@]3(C)C(CCC4[C@@]5(C)CCCC(C)(C)C5CC[C@]43C)C2[C@@H]1C</smiles>

Taraxastane the information and resources presented in this review. The following keyword combinations were used for the search: "immunomodulator" or "immunosuppressant" or "immunostimulant" or immunoadjuvant" "immune system" or "immune response" and "triterpenes". While searching, no filter was applied and no time interval was determined. The article language was restricted to English. In addition, references listed in selected articles were examined to identify additional reports not included in the databases. We selected recent accessible studies investigating the immunomodulatory effect of triterpene compounds in preclinical and clinical trial models and discussing possible mechanisms of action through specific cytokine-mediated signaling pathways. Preclinical studies with high doses which are not applicable to human consumption were excluded. In the presence of more than one study that reached the same conclusion, current sources were taken as basis. 


\section{Oleanane type triterpenes}

Oleanolic acid

Oleanolic acid (3ß-hydroxyolean-12-en-28- oic acid) (Fig. 2) is a pentacyclic triterpenoid compound that takes its name from the plant Olea europaea L. and is commonly found in the Oleaceae family. Olive fruit, apple peel, ginseng, papaya fruit and dark plums are rich sources of oleanolic acid, indicating it occurs widely in many plant families like Rosaceae, Araliaceae, and Caricaceae. Studies have shown that the compound has anti-oxidant, anti-inflammatory, antiviral, anti-cancer and immunomodulatory effects (Sen 2020).

There are many studies investigating the effects of oleanolic acid on the immune system in the literature. In one study, oleanolic acid $(50 \mu$ moles $/ \mathrm{kg}$ body $\mathrm{wt} /$ dose/animal, 5 days, i.p) was shown to increase total white blood cells $(13.575 \pm 6.4 \%)$, $\alpha$-esterase positive cells $(35.48 \pm 6.3 \%)$, bone marrow cell counts $(91.3 \pm 8.6 \%)$ and plaque-forming cells in the spleen $(148.4 \pm 5.4 \%)$ in BALB/c mice. In this study, the production of specific antibodies increased after antigen administration in animals treated with oleanolic acid. In addition, oleanolic acid inhibited delayed-type hypersensitivity reaction (88\%) (Raphael and Kuttan 2003). Córdova et al. (2014) reported that administration of oleanolic acid $(50 \mathrm{mg}$ / $\mathrm{kg}$ body weight/day, i.p) downregulated the expression levels of IL-13 and IL-33 in serum and conjunctival tissue in a Ragweed pollen-specific allergic conjunctivitis mouse model. IL-13 and IL-33 are Th2 cytokines that play a role in diseases mediated by hypersensitivity reactions such as asthma, allergic

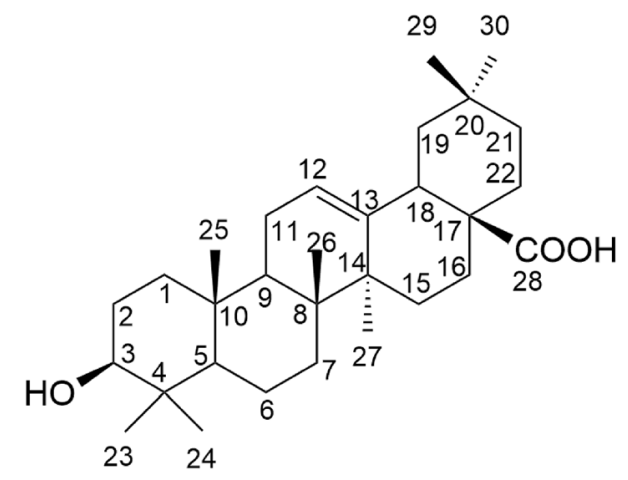

Fig. 2 Structure of oleanolic acid conjunctivitis, and rhinitis. It was determined that phospholipase A2 type-IIA (sPLA2-IIA) levels were lower in mice administered oleanolic acid. sPLA2-IIA which is an acute phase reactant associated with autoimmune and allergic diseases plays a role in the activity and migration capability of eosinophils and mast cells to tissues. Moreover, oleanolic acid reduced mast cell degranulation and eosinophil infiltration in conjunctival tissue and suppressed eotaxin and MCP-1 (monocyte chemoattractant protein 1) levels in serum and conjunctiva (Córdova et al. 2014). Jehangir et al. (2019) orally administered zinc and iron complexes of oleanolic acid at a dose of $2 \mathrm{mg} / \mathrm{kg}$ body weight to rats in an ovalbumin-induced asthma model and studied the effect of these compounds on the immunopathogenesis of asthma. It was found that leukocyte, eosinophil, neutrophil, and lymphocyte counts were significantly decreased in serum and bronchoalveolar lavage fluid of rats treated with both complexes. Treatment with zinc + oleanolic acid and iron + oleanolic acid reduced the expression of IL4, IL-5, IL-13, IL-17, and TNF- $\alpha$ (Jehangir et al. 2019). In another in vivo study, it was reported by an experimental autoimmune myocarditis model in mice that oleanolic acid $(50 \mathrm{mg} / \mathrm{kg}$ body weight/day, ip) decreased the IL17A/IL-35 ratio by suppressing IL$17 \mathrm{~A}$ production and increasing IL-35 levels in mice an experimental autoimmune myocarditis model. Oleanolic acid inhibited IL-6 production and induced IL-10 production. Accordingly, a significant decrease in the IL-6/IL-10 ratio was observed. In this model, oleanolic acid did not affect the number of $\mathrm{CD}^{+}$, $\mathrm{CD}^{+}{ }^{+}$and $\mathrm{CD}^{+}{ }^{+} \mathrm{T}$ cells, $\mathrm{CD} 14^{+}$macrophages/monocytes, and CD19 + B cells. In contrast, it significantly increased the frequency of $\mathrm{CD} 4{ }^{+} \mathrm{CD} 25^{+}$Forkhead box P3 $\left(\right.$ Foxp $^{+}$) Treg cells (Martín et al. 2014). Kim et al. (2020) administered oleanolic acid (10 and $30 \mathrm{mg} / \mathrm{kg}$, orally) to C57BL/6 mice in an experimental autoimmune encephalomyelitis model. In conclusion, oleanolic acid was found to inhibit Concanavalin A (Con A) and myelin oligodendrocyte glycoprotein induced $\mathrm{T}$ cell proliferation. Oleanolic acid reduced the accumulation of inflammatory cells and CD68+ macrophages in the spinal cords of mice (Kim et al. 2020). Numerous in vivo studies have reported that oleanolic acid lowers allergen-specific antibody levels (immunoglobulin (Ig)E, IgG, IgG1 and IgG2a) and suppresses general immune responses (Córdova et al. 2014; Choi et al. 2016; Martín et al. 2014, 2012). 
Oleanolic acid blocks the activation of NF- $\kappa \mathrm{B}$ and related signaling pathways (Jehangir et al. 2019; Choi et al. 2016; Hwang et al. 2014; Kang et al. 2021). Oleanolic acid inhibited the expression of NF- $\mathrm{KB}$ target genes, including genes encoding TNF $\alpha$, cIAP2, and $\mathrm{IkB} \alpha$, in RAW 264.7 macrophage cells. It significantly suppressed MafK (a transcriptional regulator that modulates NF- $\kappa \mathrm{B}$ activity) expression and MafK-mediated p65 acetylation. It also induced the expression of nuclear factor erythroid 2-related factor 2 (Nrf2, transcription factor that inhibits inflammation) and Nrf2 target genes including NAD(P)H:quinone oxidoreductase 1 (NQO1) and heme oxygenase1 (HO-1) (Hwang et al. 2014). Martín et al. reported that oleanolic acid $(5-15 \mu \mathrm{M})$ reduced the activity and phosphorylation of extracellular signal-regulated kinases (ERK) 1/2 and ribosomal protein S6, which are key components of mitogen-activated protein kinase (MAPK) and the mechanistic target of rapamycin signal transduction pathways, respectively, in mouse BV2 microglial cells. In addition, it inhibited proliferative response and phagocytosis in BV2 microglial cells (Martín et al. 2012). Studies have shown that oleanolic acid suppresses the production of COX-2 and iNOS enzymes, reducing prostaglandin E2 (PGE2) and nitric oxide (NO) levels, respectively, and inhibiting matrix metalloproteinase (MMP)-1 and MMP3 synthesis (Hwang et al. 2014; Martín et al. 2012; Jehangir et al. 2019; Choi et al. 2016).

Oleanolic acid blocked TLR-3 activation and inhibited mRNA expression levels of target molecules associated with the TLR3 signaling pathway, including MCP-1, IL-1 $\beta$, IL-8, VCAM-1 and ICAM-1. Oleanolic acid significantly suppressed IKKa/ $\beta$ phosphorylation and reduced the degredation of inhibitor of $\kappa \mathrm{B}(\mathrm{I} \kappa \mathrm{B})$. It is suggested that oleanolic acid inhibited TLR3 signaling, especially by interacting with IKKa/ $\beta$ (Lim et al. 2019). It also suppressed the protein levels of TLR2, MyD88, interleukin 1 receptor-associated kinase (IRAK)-4, TNF receptor associated factor 6 and p-IкB $\alpha$ (Kim et al. 2020). Oleanolic acid $(1-25 \mu \mathrm{M})$ blocked STAT1 and STAT3 activity in 3T3-L1 adipocytes. Tyk2 (an upstream kinase of STAT) signal activation was significantly suppressed in the presence of $5 \mu \mathrm{M}$ oleanolic acid. In addition, Suppressor of Cytokine Signaling 3 (SOCS3) expression was reduced by oleanolic acid (Kim et al. 2013a). To support this finding, Kang et al. (2021) reported that oleanolic acid inhibits STAT1 phosphorylation and activation both in vivo and in vitro (Kang et al. 2021). Kim et al. showed that oleanolic acid upregulates Foxp3, and downregulates GATA-3 and (RARrelated orphan receptor gamma) $\mathrm{ROR} \gamma \mathrm{t}$ (Kim et al. 2014).

In general, oleanolic acid decreased pro-inflammatory cytokine levels and reduced or inhibited inflammation-related factors. The compound suppressed the production of antigen-specific antibodies in experimental animals. Possible mechanisms of action involved in immunomodulation are thought to be the inhibition of NF- $\kappa B$ and related signaling pathways, STAT, and GATA-3 signaling pathways.

Glycyrrhizin and glycyrrhetinic acid

Glycyrrhizin (glycyrrhizic acid or glycyrrhizinic acid) which is a major triterpenoid of Glycyrrhiza glabra $\mathrm{L}$. (Fabaceae), is metabolized through the gastrointestinal tract to produce glycyrrhetinic acid (enoxolone), which also naturally occurs in G. glabra. Both compounds are pentacyclic triterpenoids (Fig. 3) and have a wide range of biological effects including anticancer, anti-inflammatory, hepatoprotective, antiviral effects. Glycyrrhetinic acid exists as the $\alpha$ and $\beta$ isomer, with the latter being the major isomer. Hence, there are more studies on $\beta$-glycyrrhetinic acid and in this paper, this isomer is indicated as glycyrrhetinic acid whereas the other isomer as $\alpha$-glycyrrhetinic acid (Graebin 2017). Glycyrrhizin is used as an intravenous injection for the treatment of hepatitis in some Asian countries. This compound has been attracting attention recently as a promising agent for the treatment of SarsCov-2 (Bailly and Vergoten 2020).

Glycyrrhizin induces both T- and B-lymphocyte proliferation (Chavali et al. 1987). This compound also affects the maturation and function of dendritic cells (DCs). It enhanced the expression of surface markers including CD40, CD80, CD83, and CD86 on DCs. Glycyrrhizin also stimulated IL-12 secretion by treated DCs, resulting in strong stimulation of $\mathrm{T}$ cell growth and differentiation. DCs treated with glycyrrhizin also increased IFN- $\gamma$ and IL-10 and reduced IL-4 production, suggesting that it modulates immune responses toward a Th1 subset (Bordbar et al. 2012; Hua et al. 2012). Interestingly, glycyrrhetinic acid developed a greater Th1 immune response than Th2 response. This compound has been stated as beneficial in the treatment of Th1-disordered diseases due to 
Fig. 3 Structures of glycyrrhizin and glycyrrhetinic acid

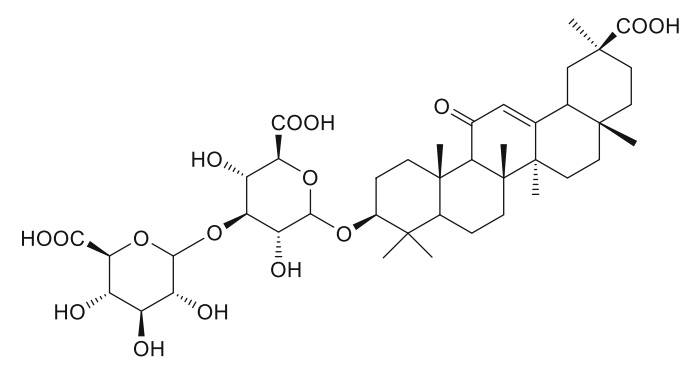

glycyrrhizin

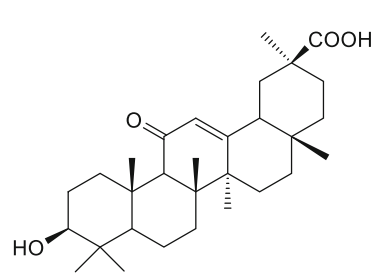

glycyrrhetinic acid
Candida albicans (Kim et al. 2013b). Glycyrrhetinic acid enhanced antibody titers of $\operatorname{IgG}$ and $\operatorname{IgM}$ in chicken immunized with Newcastle diseases vaccine and also promoted lymphocyte proliferation and the proportions of CD $4+$ and $\mathrm{CD} 8+$ in a dose- and time-dependent manner. Moreover, when this compound was encapsulated with liposomes, its effect was significantly improved (Zhao et al. 2012). 18 $\alpha$ glycyrrhetinic acid upregulated the expression of maturation markers on splenic DCs in vitro, inhibited the maturation of DCs and reduced the expression of CD40 and major histocompatibility complex-II in mice at $10 \mu \mathrm{g} / \mathrm{g}$. Furthermore, when isolated DCs were used for the mixed lymphocyte reaction assay as a continuation of the same in vivo study, it reduced DCs activation of T cells and IFN- $\gamma$ secretion. The inconsistency of data obtained by the same group has been explained as ' $18 \alpha$-glycyrrhetinic acid may have different effects on in vivo and in vitro immune parameters possibly depending on the time point and dose of treatment' (Ebrahimnezhad et al. 2016).

Glycyrrhizin also modulates the cell-mediated immune response. It enhanced $\mathrm{NK}$ cell activity, antibody titer, and antibody-dependent cell-mediated cytotoxicity in Balb/c mice bearing metastatic tumors. It decreased the elevated levels of IL- 6 and IL-1 $\beta$. It also ameliorated the decreased levels of IL-2. It also increased bone marrow cellularity and total white blood cell count (Raphael and Kuttan 2003, 2008).

TLRs are playing an important role by modulating several immune responses, especially during infection. Glycyrrhizin especially alters TLR-4, a key receptor of the innate immune signaling responses, particularly against respiratory viruses. It suppressed TLR4/MD-2-mediated innate immune responses. It inhibited lipopolysaccharide (LPS) binding to the TLR4/MD-2 complex. Glycyrrhizin also inhibited
LPS-triggered TLR4 internalization. Of note, this triterpene inhibits not only TLR4- but also TLR9mediated inflammatory responses by reducing $\mathrm{CpG}$ DNA uptake in RAW264.7 mouse macrophages (Honda et al. 2012; Schröfelbauer et al. 2009). Glycyrrhetinic acid induced the expression of TLR4 and its downstream signaling molecules, expression of IFN- $\beta$ and IL- 6 through the adaptor molecule MyD88 in Ana-1 murine macrophages (Peng et al. 2011).

Glycyrrhizin also modulates the immune system by altering some chemokines. It reduced the $\mathrm{H} 5 \mathrm{~N} 1$ virusinduced production of chemokine CXCL-10, and chemokine ( $\mathrm{C}-\mathrm{C}$ motif) ligand $(\mathrm{CCL}) 5$. Further, it down-regulated $\mathrm{TNF} \alpha$ - and IL-4-induced eotaxin 1 production via NF- $\mathrm{KB}$ and STAT3 in human lung fibroblasts (Matsui et al. 2006; Michaelis et al. 2010).

Glycyrrhizin decreased the production of inflammation-related cytokines, IL-1 $\beta$, IL-3, IL-5, IL-6, IL10 , IL-12, IL-13 IFN- $\gamma$, TNF- $\alpha$, and IL-17. In addition, it inhibited some other inflammatory molecules like high mobility group box 1 (HMGB1), iNOS, and COX-2 (Chen et al. 2017; Han et al. 2017; Liu et al. 2014; Wang et al. 2015a, b). Treatment with $50 \mathrm{mg} / \mathrm{kg}$ glycyrrhetinic acid for 5 days decreased IL-10 and IL4 levels but enhanced IL-12, IFN- $\gamma$, and TNF- $\alpha$ levels associated with differentiation of Th2 to Th1. NF- $\kappa B$ activation involves the induction of the production of pro-inflammatory mediators (Ukil et al. 2011). Several studies proved the anti-inflammatory actions of glycyrrhizin, $\alpha$ and $\beta$ - glycyrrhetinic acid. These compounds inhibited PLA2/arachidonic acid pathway metabolites including PGE 2, prostacyclin 2, thromboxane 2, and leukotriene B4. They also decreased ICAM-1 and MMP-9. Additionally, these triterpenes boosted the antioxidant defense system by enhancing the activity of superoxide dismutase, glutathione peroxidase, and catalase, which in turn, increased 
total antioxidant capacity. Inhibition of MAPK pathway components including JNK, p38, and ERK as well as $\mathrm{NF}-\kappa \mathrm{B}$ pathway involves in anti-inflammatory actions of these triterpenes (Honda et al. 2012; Li et al. 2011; Wang et al. 2015a, b). HMGB1 has been suggested to contribute to the pathogenesis of various chronic inflammatory and autoimmune diseases. It is therefore a therapeutic target for some central nervous system diseases. Glycyrrhizin not only inhibits the expression of HMGB1, but also translocation, and release of HMGB1 in astrocytes as well as microglia (Li et al. 2018).

Glycyrrhizin attenuated the increased IL-4 level and restored the immune balance of Th1/Th2 cells in a dose-dependent manner. Moreover, it attenuated the B cells that produce allergen-specific $\operatorname{IgE}$ and $\operatorname{IgG} 1$ in three models of allergic reaction in vivo and in vitro. It inhibited mast cell degranulation and decreased vascular permeability by inhibiting the expression of calcium channel proteins and blocking extracellular $\mathrm{Ca}^{2+}$ influxes (Han et al. 2017).

Effect of glycyrrhizic acid ammonium salt, a glycyrrhizin derivative was tested by using an immune-mediated hepatitis model. $50 \mathrm{mg} / \mathrm{kg}$ or $100 \mathrm{mg} / \mathrm{kg}$ glycyrrhizic acid ammonium salt treatment for 10 days alleviated Con A-induced liver injury and increased the survival rate of mice. However, these doses may not be reached in human applications. It reduced increased inflammatory factors like IL-1 $\beta$, IL-6, TNF- $\alpha$, IFN- $\gamma$, and IL-17A and regulated the balance of Th1/Th2/Treg/Th17, some immunoregulators, in the liver cells. Further, glycyrrhizic acid ammonium salt also inhibited hepatocyte apoptosis via inhibition of Janus kinase (JAK1)/ signal transducers and activators of transcription (STAT1)/(Interferon Regulatory Factor 1) IRF1 (Tian et al. 2019).

The ability of glycyrrhetinic acid to inhibit potassium channels (Kv1.3channels) may also contribute to its anti-inflammatory and immunomodulatory actions (Fu et al. 2013).

There are several clinical trials on glycyrrhizin and glycyrrhetic acid related to their anti-inflammatory or immunomodulatory actions. Effects of glycyrrhizin on liver function and cellular immunity of children with infectious mononucleosis complicated liver impairment were assessed in 62 children. Volunteers were divided into a healthy group, a control group, and a glycyrrhizic acid group. Both control and glycyrrhizic acid groups were treated with conventional therapy, but the glycyrrhizic acid treated group, was given additionally once a day IV glycyrrhizic acid for 2 weeks. $\mathrm{CD}^{+}, \mathrm{CD}^{+}, \mathrm{CD}^{+}$, and $\mathrm{CD} 4^{+} / \mathrm{CD}^{+}$ratio with were assessed. In addition to conventional therapy, glycyrrhizin altered markers almost similar to the levels of healthy groups (Zong-xin et al. 2006).

In a randomized clinical trial, the effect of glycyrrhizin in patients with chronic urticaria was evaluated. 84 patients with urticaria were randomized in two groups: $50 \mathrm{mg}$ glycyrrhizin 3 times daily and levocetirizine was administered for four weeks. At the end of the study, it was concluded that glycyrrhizin treatment gave better results than levocetirizine treatment. In another clinical trial on 39 children with Henoch-Schonlein purpura, glycyrrhizin altered IL17. However, it did not change TGF- $\beta$ and IL-10 serum levels after the treatment (Graebin 2017). It is suggested that pro-inflammatory cytokines might play a crucial role in the pathophysiology and treatment of depression. In a study conducted on 56 patients with depression treated with either selective serotonin reuptake inhibitor + glycyrrhizin or selective serotonin reuptake inhibitor + placebo. After 4 weeks of treatment, TNF- $\alpha$ level reduced and symptomatic improvement existed in patients with high-inflammation (baseline CRP $>3 \mathrm{mg} / \mathrm{L}$ ) rather than those with low-inflammation (baseline $\mathrm{CRP} \leq 3 \mathrm{mg} / \mathrm{L}$ ) in the glycyrrhizin group (Cao et al. 2020). Psoriasis is an inflammation-related immune system disease and a meta-analysis suggested that glycyrrhizin in combination with conventional therapy enhances clinical response without any additional risk in the treatment of psoriasis (Yu et al. 2017). Allergic rhinitis is an IgEmediated inflammatory reaction. In a clinical trial, patients with allergic rhinitis were treated with glycyrrhetic acid or mometasone furoate nasal spray for 60 days. At the end of the study, the findings showed that nasal endoscopic signs, perception of symptoms, and nasal functions were significantly improved without significant differences from the mometasone furoate group. Moreover, glycyrrhetic acid is better tolerated (Gariuc et al. 2020). However, there are several limitations of clinical trials. Especially subject groups are relatively small. Therefore, properly designed clinical studies are needed.

Overall, glycyrrhizin and glycyrrhetic acid modulate the immune system by different mechanisms related to anti-inflammatory effect, mainly via 
inhibition of NF- $\mathrm{KB}$ and MAPK pathways. Hence, they are suggested as potential candidates for the prevention of cytokine storms.

Friedelane type triterpenes:

\section{Celastrol}

Celastrol is a pentacyclic triterpenoid belonging to the quinone methide (Fig. 4) class isolated from the roots of Tripterygium wilfordii Hook F (Celastraceae). It exhibited immunosuppressant, anti-inflammatory, and anti-tumoral activities (Hou et al. 2020).

Administration of celastrol $(1 \mathrm{mg} / \mathrm{kg} / \mathrm{day}$, i.p) reduced the number of CD $4+\mathrm{T}$ and $\mathrm{CD} 8+\mathrm{T}$ cells in the joints in the rat adjuvant arthritis model ( $p<0.05)$ (Astry et al. 2015). Moreover, celastrol treatment $(1 \mathrm{mg} / \mathrm{kg} / \mathrm{day}$, i.p $)$ decreased the CD3 $+\mathrm{T}$ lymphocyte count (celastrol: $6.80 \pm 0.90$, vehicle: $22.70 \pm 1.38, \mathrm{p}<0.001)$ in rats with autoimmune encephalomyelitis (Abdin and Hasby 2014).

Celastrol reduced the Th17/Treg cell balance by inhibiting the differentiation of Th17 cells and inducing differentiation of Treg cells. Celastrol suppressed the expression of Th17 specific genes such as STAT3, SOCS3, and ROR $\gamma \mathrm{t}$ (regulates Th17 cell differentiation) (Astry et al. 2015; Wang et al. 2015a, b). Zhang et al. (2018) reported that celastrol increased Treg differentiation by inducing Foxp3 expression and altering their metabolism. It suppressed glycolysis and promoted fatty acid metabolism, both of which play an important role in organelle biogenesis in $\mathrm{T}$ cells (Zhang et al. 2018).

In one study, human hepatocellular carcinoma cells were incubated with celastrol at concentrations ranging from 0.5 to $5 \mathrm{M}$. In addition to STAT3 inhibition,

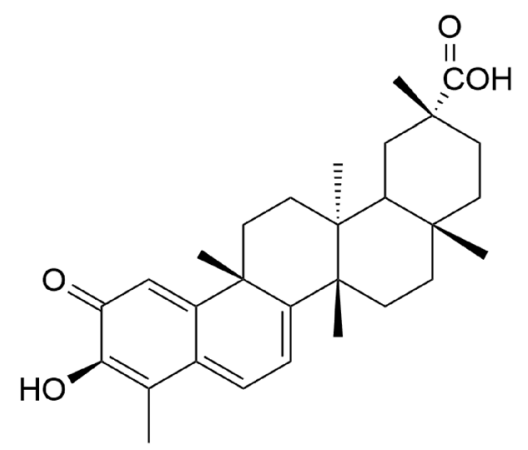

Fig. 4 Structure of celastrol activation of protein kinases including c-Src kinase, JAK-1, and JAK-2 were also inhibited in a dosedependent manner (Rajendran et al. 2012). Celastrol inhibited the NF- $\kappa \mathrm{B}$ signal pathway. It significantly blocked cytokine-induced signal cascades, including

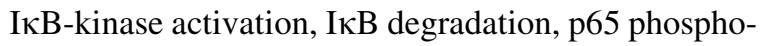
rylation, and p65 DNA binding activity leading to NF$\kappa \mathrm{B}$ activation (Ju et al. 2015).

Celastrol suppressed the productions of IL-1 $\beta$, IL6, IL17 (Th17 specific cytokine), and TNF- $\alpha$ by inhibiting phosphorylation of MAPK/ERK1/2 and activation of NF- $\kappa$ B (Jung et al. 2007; Wang et al. $2015 a, b)$. Celastrol decreased mature IL- $1 \beta$ release by inhibiting caspase-1, serine protease, and MMP-9 enzymes, which are involved in the production and release of mature IL-1 $\beta$ from proIL-1 $\beta$ (Astry et al. 2015). This compound also inhibited cytokine-induced iNOS, COX-2, MMP-1, MMP-3, MMP-13, and CCL2 expressions in different experimental models (Ding et al. 2013; Ju et al. 2015). Celastrol downregulated TLR2 expression and suppress TLR4 activation by inhibiting the binding of LPS to the TLR4/MD2 myeloid differentiation factor 2) complex (Abdin et al. 2014; Lee et al. 2015).

Celastrol exerted an immunosuppressive effect by changing the Th17/Treg balance. The most likely mechanism for reducing the Th17/Treg balance is NF$\kappa \mathrm{B}$ inhibition. Celastrol suppressed the expression of genes associated with pro-inflammatory cytokines (TNF, IL-1, IL-6, IL-17) and chemokines, inflammatory enzymes (COX-2, 5-LOX), and iNOS. It also inhibited TLRs. The underlying mechanism of these effects is inhibition of the NF- $\mathrm{KB}$ signaling pathway.

\section{Pristimerin}

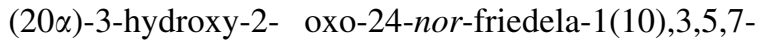
tetraen-carboxylic acid- (29)-methyl ester namely pristimerin (Fig. 5) is a triterpenoid quinone methide found in Celastraceae and Hippocrateaceae families and known for its anti-inflammatory activity.

The activity of pristimerin on the iNOS system was investigated in LPS-induced RAW 264.7 macrophages. It reduced nitrite accumulation, a parameter for NO synthesis, dose-dependently $\left(\mathrm{IC}_{50}: 0.2-0.3\right.$ $\mu \mathrm{M})$ in supernatants of LPS-stimulated macrophages through a mechanism involving inhibition of NFKB activation and it may also affect various other gene products regulated by NFkB (Dirsch et al. 1997). Jin 


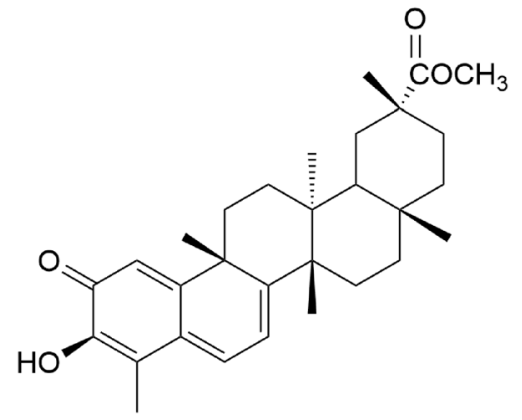

Fig. 5 Structure of pristimerin

et al. (2016) performed another study demonstrating the inhibitory effect of pristimerin on MAPKs and NF$\kappa \mathrm{B}$ inflammatory pathways and demonstrated the inhibitory effect of pristimerin on the translocation of NF- $\kappa \mathrm{B}$ from the cytoplasm to the nucleus after ovalbumin challenge in a dose-dependent manner. This is important because NF- $\kappa \mathrm{B}$ activity is controlled by chemical modifications like phosphorylation and interactions with other proteins, particularly members of the IкB family (Jin et al. 2016). Activation of innate immunity-related TLR signals leads to activation of $\mathrm{NF}-\kappa \mathrm{B}$ and the expression of pro-inflammatory gene products such as cytokines and iNOS. Kim et al. (2019) found that pristimerin suppresses iNOS expression induced by MALP-2 (TLR2 and TLR6 agonist), Poly[I:C] (TLR3 agonist), or LPS (TLR4 agonist).

Pristimerin suppressed T lymphocyte proliferation associated with the inhibition of IL-2 induced Jak/ STAT and Erk1/2 signaling pathways. Inhibition of the NF- $\mathrm{BB}$ pathway also involved the suppression of IL-2 induced $\mathrm{T}$ lymphocyte proliferation by pristimerin (Liu et al. 2016).

Tong et al. (2014) found that pro-inflammatory cytokines (IL-6, IL-17, IL-18, and IL-23) and IL-6/IL17-associated transcription factors (pSTAT3 and ROR- $\gamma \mathrm{t}$ ) were reduced as well, while IL-10 (an immunomodulatory cytokine) and IFN- $\gamma$ (that inhibits IL-17 response) were increased in pristimerin-treated rats.

All in all, pristimerin suppresses $\mathrm{T}$ cell responses by inhibition of the NF- $\mathrm{B}$ pathway and IL-2 induced activation of the Jak1/STAT5 and Erk1/2 signaling pathways.
Ursane type triterpenes:

\section{Ursolic acid}

Ursolic acid (3ß-hydroxy-urs-12-en-28-oic acid) is a ursane-type pentacyclic triterpenoid (Fig. 6). The compound was isolated from different organs of plants such as Rosmarinus officinalis L., Origanum majorana L., Thymus vulgaris L., Malus domestica Borkh., Lavandula angustifolia Mill., and Sambucus nigra L. And the compound was found to have antioxidant, anti-inflammatory, and anti-cancer activities (Hussain et al. 2017).

Ursolic acid has been shown to affect immune functions in different experimental animal models. Raphael and Kuttan (2003) reported that ursolic acid (50 $\mu \mathrm{moles} / \mathrm{kg}$ body wt/dose/animal, 5 days, i.p) increased the number of total white blood cells $(91.48 \pm 4.6 \%), \quad \alpha$-esterase positive cells $(19.3 \pm 2.3 \%)$, and plaque-forming cells in the spleen $(201 \pm 3.1 \%)$ in $\mathrm{BALB} / \mathrm{c}$ mice. A significant enhancement in specific antibody production was observed following antigen administration in animals treated with ursolic acid. In addition, ursolic acid inhibited the delayed-type hypersensitivity reaction (76\%) (Raphael and Kuttan 2003). Xu et al. (2015) studied the effect of ursolic acid (20 and $100 \mathrm{mg} /$ $\mathrm{kg} /$ day, i.p) on immune functions in an experimental autoimmune myasthenia gravis model. Ursolic acid induced apoptosis by upregulating Fas expression in mononuclear cells in lymph nodes at both doses. Both the doses increased IL-10 levels and decreased IL-17A levels in MNCs. At high dose, $100 \mathrm{mg} / \mathrm{kg} /$ day, enhanced the number of CD4 ${ }^{+}$Foxp $3{ }^{+}$and CD25 ${ }^{+}$Foxp $3{ }^{+} \mathrm{T}$ cells and reduced the levels of IgG2b anti-AChR antibodies in the serum (Xu et al. 2015). In another in vivo study, ursolic acid $(20 \mathrm{mg} / \mathrm{kg}$, p.o) suppressed ovalbumin-specific IgE production and

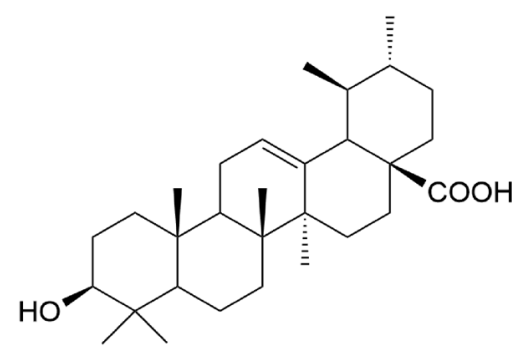

Fig. 6 Structure of ursolic acid 
inhibited Th2 (IL-5, IL-13) and Th17 (IL-17) cytokine production in an ovalbumin-induced asthma model (Kim et al. 2013a, b, c). Contrary to this finding, Ahmad et al. (2006) found that ursolic acid (10, 20, 40, 80 , and $160 \mathrm{mg} / \mathrm{kg}$, oral) dose-dependently induced Th2 (IL4, IL5) cytokine expression in their adjuvant arthritis model in rats (Ahmad et al. 2006). In vivo studies revealed that ursolic acid reduces Th1 cytokine expression (IL-2, IL-6, IL-12, IFN- $\gamma$ and TNF- $\alpha$ ) (Ahmad et al. 2006; Chun et al. 2014). Unlike these studies, ursolic acid $(0.05 \% \mathrm{w} / \mathrm{w}, 4$ weeks) activated T cells by significantly increasing IL- 2 and IFN- $\gamma$ production of $\mathrm{T}$ cells in response to Con A stimulation in lymphocyte proliferation assay in type 1 diabetic mice fed a high-fat diet. In this study, TNF- $\alpha$ production was inhibited in response to LPS stimulation in B cells, similar to the results of other studies. $\mathrm{CD} 4+, \mathrm{CD} 8+$ and $\mathrm{CD} 19+$ numbers did not change after treatment with ursolic acid (Jang et al. 2009).

Several clinical studies evaluated the effects of ursolic acid on cytokine levels. In a randomized controlled trial, ursolic acid $(3 \times 1$ capsule, 8 weeks $)$ supplementation combined with High-Intensity Resistance Training was administered to twenty-two healthy and low-activity male volunteers. As a result, it was determined that ursolic acid supplementation significantly reduced plasma levels of CRP, IL- 6 and TNF- $\alpha$ compared to placebo $(p<0.05)$ (Asghari et al. 2020). In a randomized, double-blind, placebo-controlled clinical trial, 24 patients with a diagnosis of metabolic syndrome were treated with ursolic acid $150 \mathrm{mg}$ daily for 12 weeks. Consequently, ursolic acid administration did not affect serum inflammation parameter levels (IL-6, CRP) (Ramírez-Rodríguez et al. 2017). Overall, though studies shows immunoregulatory property of ursolic acid, subject groups were small. Hence, more well-designed studies with biger subject group should be conducted.

Ursolic acid inhibits the activation of NF- $\kappa \mathrm{B}$ and related signaling pathways in a range of human cell lines (Shishodia et al. 2003; Chun et al. 2014; Kim et al. 2013a; Jang et al. 2014). Ursolic acid inhibited I $\kappa \mathrm{B} \alpha$ degradation, I $\kappa \mathrm{B} \alpha$ phosphorylation, I $\mathrm{B} \alpha \alpha$ kinase activation, p65 phosphorylation, p65 nuclear translocation, and NFKB-dependent reporter gene expression. It reduced the expression of NFkB-dependent cyclin D1, COX-2, and MMP-9 (Shishodia et al. 2003; Chun et al. 2014). In peritoneal macrophages, ursolic acid $(5,10$, and $20 \mu \mathrm{M})$ treatment significantly blocked LPS-induced phosphorylation of interleukin 1 receptor-associated kinase 1 (IRAK1), IRAK4, transforming growth factor- $\beta$-activated kinase 1 proteins. In this study, ursolic acid inhibited ERK, JNK, and p38 phosphorylation and suppressed MAPK activation. In addition, it decreased the expression levels of LPS-induced COX-2 and iNOS and reduced the levels of PGE2 and NO (Jang et al. 2014). A molecular docking study showed that ursolic acid binds to the phosphorylation and catalytic sites of the ERK protein, leading to ERK inhibition $(\mathrm{Ki}=2.42$ $\mu \mathrm{M}$ and $7.66 \mathrm{kcal} / \mathrm{mol}$ ) (Pratap et al. 2016). Ursolic acid $\left(10^{-5} \mathrm{M}, 1 \mathrm{~h}\right.$ incubation) blocked the activation of TLR4/MyD88 signaling pathway induced by LPS and reduced the release of inflammatory cytokines including TNF- $\alpha$, IL-6, and IL-1 $\beta$ (Zhao et al. 2019). Kim et al. (2013a, b, c) reported the inhibitory effect of PPAR $\gamma$ agonists on the expression of pro-inflammatory cytokines such as TNF- $\alpha$, IL-1 $\beta$, and IL-6. PPAR $\gamma$ mRNA expression and PPAR $\gamma$ protein expression were significantly increased in EL4 and RAW 264.7 cells treated with ursolic acid. It has been shown that ursolic acid can decrease the production of $\mathrm{Th} 2$ (IL-5, IL-13) and Th17 (IL-17) cytokines by suppressing the GATA-3 and STAT-6 pathways (Kim et al. 2013a, b, c). Xu et al. (2011) demonstrated that ursolic acid suppresses IL-17 production by selectively antagonizing the function of ROR $\gamma \mathrm{t}$ (IC50 = $0.68 \pm 0.1 \mu \mathrm{M})(\mathrm{Xu}$ et al. 2011). Contrary to these findings, one in vitro study showed that preincubation of RAW 264.7 mouse resting macrophage cells with ursolic acid $(1,5$ ve $10 \mu \mathrm{M})$ enhanced the concentration-dependent production of NO and TNF- $\alpha$ and expression of iNOS mRNA and TNF- $\alpha$ mRNA via $\mathrm{NF}-\kappa \mathrm{B}$ transactivation. The authors stated that ursolic acid has a dual effect. Although it reduces LPSinduced NO production and iNOS expression, it induces basal (intrinsic) NO and TNF- $\alpha$ production (You et al. 2001).

Ursolic acid (10, 25, and $50 \mu \mathrm{M})$ dose-dependently inhibited IL-6-induced STAT3 and STAT3 phosphorylation in human liver cancer cell lines in vitro. Simultaneously, ursolic acid suppressed the phosphorylation of JAK2 (a kinase involved in STAT3 activation) and decreased the expression of STAT3 downstream target genes such as Bcl-2, Bcl-xl, survivin. Ursolic acid improved the expression levels of cleaved caspase-3. It did not affect the 
phosphorylation of STAT3 and STAT3 induced by leukemia inhibitory factors. In the continuation of this study, ursolic acid was administered at a dose of $60 \mathrm{mg} / \mathrm{kg} /$ day in the HEPG2 mouse xenograft model. The results of the in vivo study confirmed the in vitro findings. Ursolic acid inhibited STAT3 phosphorylation, decreased Bcl-2 expression, and induced cleavage of caspase-3 (Liu et al. 2017).

In conclusion, ursolic acid exerts an immunomodulatory effect by affecting different signaling pathways such as NF- $\kappa \mathrm{B}$, STAT, and GATA, and the release of various mediators associated with these pathways.

Boswellic acids

Boswellic acids are pentacyclic triterpenes (Fig. 7), found in oleo gum resin of Boswellia serrata Roxb. and Boswellia carteri Birdw. (Burseraceae). 3-Oacetyl-11-keto- $\beta$-boswellic acid, 11-keto- $\beta$-boswellic acid, 3- $O$-acetyl- $\beta$-boswellic acid, 3- $O$-acetyl- $\alpha$ boswellic acids, $\alpha$ and $\beta$-boswellic acids are major triterpenes of these resins. Among boswellic acids, especially 3-O-acetyl-11-keto- $\beta$-boswellic acid and 11 -keto- $\beta$-boswellic acid were well studied. Boswellic acids possess anti-inflammatory and immunoregulatory actions by different mechanisms (Roy et al. 2019).

A single oral dose of a mixture of boswellic acids $(50-200 \mathrm{mg} / \mathrm{kg}$ ) on the day of sensitization produced a dose-dependent decrease (10.4-32.8\%) in primary hemagglutinating antibody titers in the serum of mice treated with sheep erythrocytes. Interestingly, the same mixture increased secondary antibody titers at
$50 \mathrm{mg} / \mathrm{kg}$ whereas, this response was lower in the higher doses (100 and $200 \mathrm{mg} / \mathrm{kg}$ ). The lowest dose, $25 \mathrm{mg} / \mathrm{kg}$, enhanced primary antibody titers by more than that of 50 and $100 \mathrm{mg} / \mathrm{kg}$ when given for 5 days (starting 2 days before immunization and continued for 2 days). Of note, this mixture increased primary humoral response in a dose-dependent manner, it did not alter secondary humoral response significantly when it was given 7 days before immunization (Sharma et al. 1996).

Boswellic acid mixture at the doses of $1.95-125.0 \mu \mathrm{g} / \mathrm{ml}$ did not exhibit any spontaneous mitogenic activity in non-immunized mice spleen cells. However, when the presence of mitogen stimulating agents was used for the same test, it inhibited the proliferation of $\mathrm{T}$ lymphocytes in a dose-dependent manner (Sharma et al. 1996). Several studies have also shown that different boswellic acids either alone or as a mixture inhibited $\mathrm{T}$ lymphocyte proliferation at non-cytotoxic concentrations (Wang et al. 2018; Zimmermann-Klemd et al. 2020). On the contrary, Badria et al. reported that some boswellic acids, isolated from the gum resin of B. serrata induced T-lymphocyte proliferation with EC50 values from 0.001 to $0.005 \mu \mathrm{M}$ (Badria et al. 2003). Disputably, some authors conclude that low concentrations of boswellic acids increase the stimulated proliferation of lymphocytes, but higher concentrations are inhibitory although experimental conditions are not comparable. This assumption is consistent with the study of Sharma et al. (1996) as lower doses of boswellic acids enhanced antibody titers whereas higher doses decreased the antibody titers (Ammon 2010; Sharma et al. 1996).
Fig. 7 Structures of some boswellic acids

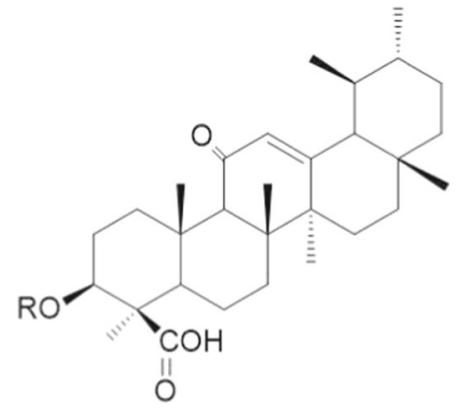

R: H

R: Acetyl 11-keto- $\beta$-boswellic acid

3-acetyl-keto- $\beta$-boswellic acid

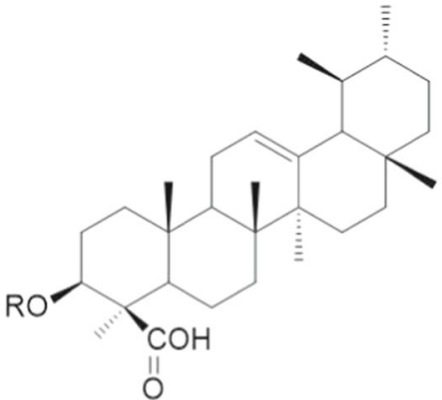

R: H

$\beta$-boswellic acid

R: Acetyl 
Pre-incubation of macrophages with $1.95-125 \mu \mathrm{g} /$ $\mathrm{mL}$ boswellic acids mixtures enhanced phagocytosis. The highest effect was observed at $62.25 \mu \mathrm{g} / \mathrm{mL}$, after this concentration the enhancement reduced (Sharma et al. 1996).

Antigen-antibody reactions take place on the surface of mast cells leading to degranulation of mast cells, in turn, mast cells release some mediators. Oleo gum resin of B. serrata extract, containing $60 \%$ acetyl 11-keto $\beta$-boswellic acid along with other boswellic acids like 11-keto $\beta$-boswellic acid, acetyl $\beta$-boswellic acid, and $\beta$-boswellic acid inhibited granulation of mast cells at 40 and $80 \mathrm{mg} / \mathrm{kg}$ doses in allergeninduced passive anaphylaxis model (Pungle et al. 2003).

Acetyl 11-keto $\beta$-boswellic acid decreased the activation of dendric cells, inhibited the mRNA expression and secretion of IL-12 and IL-23. This compound inhibited the maturation and differentiation of DCs to promote T-cell differentiation and downregulated the activation of TLR7/8 and IRF signaling pathways (Wang et al. 2018). Not only natural boswellic acids but also some synthetic derivatives, including a series of 3-acyl analogues including their epimers and 4-amino analogs inhibited pro-inflammatory cytokines, TNF- $\alpha$ and IL-6. Acyl analogs of 11-keto- $\beta$-boswellic acid with short carbon chain enhanced TNF- $\alpha$ inhibition whereas higher acyl homologs of $\beta$-boswellic acid exhibited better TNF$\alpha$ inhibition. Furthermore, epimerization at $3-\mathrm{OH}$ in both 11-keto- $\beta$-boswellic acids and $\beta$-boswellic acid increased TNF- $\alpha$ inhibition. Higher acyl homologs inhibited IL-6 better than lower acyl homologs (Sharma et al. 2016).

Both the resin extracts of $B$. serrata (containing boswellic acids mixture) and different boswellic acids downregulated pro-inflammatory cytokines including TNF- $\alpha$, IL-1 $\beta$, IL-2, IL-4, IL-6, and IFN- $\gamma$ in vitro and in vivo (Ammon 2019; Cuaz-Pérolin et al. 2008; Gayathri et al. 2007; Syrovets et al. 2005). Several studies showed that acetyl 11-keto $\beta$-boswellic acid, acetyl $\alpha$-boswellic acid inhibited the expression of pro-inflammatory cytokines such as TNF- $\alpha$, which is associated with inhibition of NF- $\kappa \mathrm{B}$ and MAPK pathways (Sengupta et al. 2009; Syrovets et al. 2005; Wang et al. 2018). There is also a clinical trial proving that boswellic acids reduce plasma inflammatory markers such as TNF- $\alpha$, IL-1 $\beta$, IL-6, IL-8, and PGE2 compared to placebo (Baram et al. 2019).
Acetyl-11-keto- $\beta$-boswellic acid decreased the differentiation of $\mathrm{CD} 4+\mathrm{T}$ cells to Th17 cells but increased Th2- and Treg-cell differentiation. Moreover, it downregulated IL-1 $\beta$-induced IRAK1 phosphorylation and IL-1 $\beta$-induced STAT3 phosphorylation, which have an important role in Th17 cell differentiation (Stürner et al. 2014).

Boswellic acids also altered leukotriene and prostaglandin synthesis. Futhermore some boswellic acids inhibited 5-lipoxygenase, COX-1, and COX-2 (Ammon et al. 1991). Apart from the other effects, the glucocorticoid receptor regulatory actions of certain boswellic acids also contribute to their immunoregulatory and anti-inflammatory potentials (Karra et al. 2020).

An in vitro immunohaemolysis assay showed that a mixture of Boswellic acids inhibited the classical complement system through inhibition of the conversion of C3 into C3a and C3b (Kapil and Moza 1992).

In general, boswellic acids exert either an immunostimulating or immunosuppressive effect, depending on the doses and antigen presentation. They altered cell-mediated and humoral immune responses. Activity mechanisms generally associated with their anti-inflammatory action.

Lupane type triterpenes:

\section{Lupeol}

Lupeol is a pentacyclic triterpene, which is the form of lupan in which hydrogen at the $3 \beta$ position is replaced by a hydroxy group (Fig. 8). It exhibits anti-diabetic, anti-inflammatory, anti-cancer, anti-microbial, antiprotozoal effects. It found in many vegetables and fruits including, pepper, cucumber, tomato, carrot,

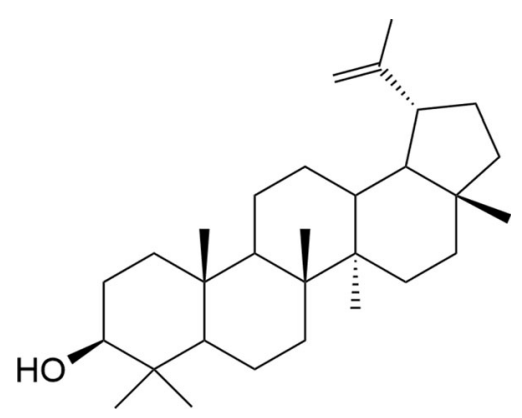

Fig. 8 Structure of lupeol 
figs, strawberries, and grapes (Siddique and Saleem 2011).

Lupeol showed immunomodulatory activity by increasing macrophage phagocytosis and stimulating T-lymphocyte proliferation (Badria et al. 2003; Wahdaningsih et al. 2020).

Lupeol increased the levels of T cells, Th1 cytokines, NF- $\kappa \mathrm{B}$, and nitric oxide synthase genes, as well as elevated the production of reactive oxygen species and nitric oxide in vitro and in vivo against Leishmania donovani infection (Kaur et al. 2019). Similarly, lupeol stimulated the generation of NO in Leishmania donovani infected macrophages followed by up-regulation of pro-inflammatory cytokines and downregulation of anti-inflammatory cytokines (Das et al. 2017). In a different study, Bani et al. (2006) reported that oral administration of lupeol at doses of 12.5-200 mg/kg p.o. inhibited CD4 + T and CD8 + T cell counts and cytokines IL-2, IFN- $\gamma$ (Th1), and IL-4 (Th2). When the efficacy of lupeol in the treatment of bronchial asthma in BALB/c mice was assessed, it was shoen to be associated with Th2 immune response. Lupeol reduced the levels of Th2 cytokines, including IL-4, IL-5, and IL-13 this effect was similar to that observed at dexamethasone-treated mice, contrarily, IgE level was not significantly changed after treatment with lupeol (Vasconcelos et al. 2008).

According to the literature, ursolic acid and lupeol have been known to possess immunomodulatory and anti-inflammatory activities, comparable to boswellic acids, but were less active than levamisole. Structure activity relationship has been represented by QSAR model showing that their activity depends on high binding affinity to human receptors viz., NF- $\kappa \mathrm{B}$ p52 $(-50.549 \mathrm{kcal} / \mathrm{mol})$, TNF- $\alpha(-47.632 \mathrm{kcal} / \mathrm{mol})$, $\mathrm{NF}-\kappa \mathrm{B} \quad \mathrm{P} 50 \quad(-16.798 \mathrm{kcal} / \mathrm{mol})$ and COX-2 $(-55.244 \mathrm{kcal} / \mathrm{mol})$. In vivo immunomodulatory effect of the compounds was also undertaken with a 28 days oral administration study. In spite of not observing significant changes in cell mediated immune response/delayed type hypersensitivity test, gain in body weight, total red blood cell counts, total white blood cell counts and hemoglobin parameters, it was stated that ursolic acid could be considered as a potential immunomodulatory agent, since it displayed higher antibody titer at a lower dose compared to lupeol (Maurya et al. 2012).
The effect of lupeol of which anti-inflammatory effect is known, on the NF- $\kappa \mathrm{B}$ signaling pathway has been the subject of many studies. Lupeol inhibited latent infection membrane protein 1-induced NF- $\kappa \mathrm{B}$ activation in Epstein-Barr virus-transformed lymphoblastoid cell line (Kang et al. 2013). It strongly suppressed pro-inflammatory cytokine production in the human intestinal epithelial cells and murine macrophages through NF- $\kappa \mathrm{B}$. It also inhibited the DNA binding of NF- $\kappa \mathrm{B}$ via the blockage of LPSinduced I $\mathrm{B} \alpha$ phosphorylation in macrophages (Lee et al. 2016).

Overall, lupeol modulates immunity mainly by altering Th1/Th2 cytokines associated with NFkB.

\section{Betulin and betulinic acid}

Betulin and betulinic acid (Fig. 9) are lupane-type triterpenes, present in Betula species and many other plants. These triterpenes exhibit a wide range of biological activities including anti-viral, anti-inflammatory, and anti-cancer effects. Notably, anti-cancer effects of these compounds including their derivatives became the subject of intense research due to promising findings (Hordyjewska et al. 2019).

Betulin stimulated the proliferation of human lymphocytes (Ghannadian et al. 2013). Betulinic acid stimulated the proliferation of thymocytes, splenocytes, and human PBMC in a time and dose-dependent manner. It stimulated higher production of mice thymocytes than splenocytes. This showed that it supports $\mathrm{T}$ and $\mathrm{B}$ lymphocytes, however, this promotion is in favor of $\mathrm{T}$ lymphocytes (Mashitoh et al. 2012). This compound enhanced the percentage of CD4 + cells in the thymus as well as the percentage of $\mathrm{CD} 19+$ (total B cells) and the ratios of CD4 + I $\mathrm{CD} 8+$ in the spleen whereas it decreased the percentage of $\mathrm{CD} 8+$ in the spleen. Betulinic acid increased TNF- $\alpha$ levels whereas decreased concentrations of IL-2 and IL-6. These findings suggested that betulinic acid exhibits a mixed, Th1 and Th2 adjuvant activity in LPS or Con A induced test system (Yi et al. 2010; Zdzisińska et al. 2003). Similar to previous findings, this compound increased CD4 + level and the ratios of $\mathrm{CD} 4+/ \mathrm{CD} 8+$ in tumor-bearing mice. On the contrary to previous test models, it increased IL-2 levels in tumor-bearing mice (Wang et al. 2012). Betulin downregulated expressions of mRNA levels of IL-6, MCP-1, and IL-1 $\beta$. It also decreased pro- 

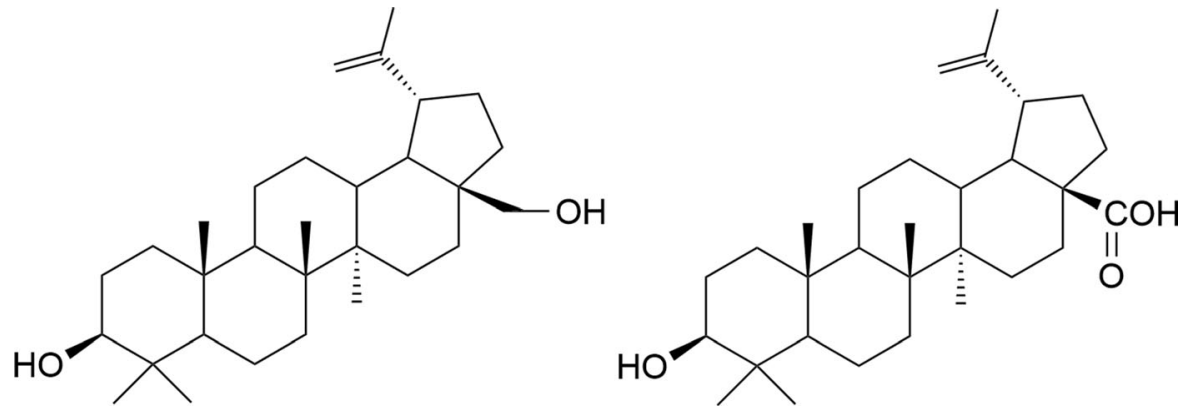

Fig. 9 Structure of betulin and betulinic acid

inflammatory cytokines including TNF- $\alpha$, IL- 6 , and IFN- $\gamma$ levels and reduced the IFN- $\gamma / \mathrm{IL}-10$ ratio. It inhibited the activation of NF- $\mathrm{KB}$ signaling associated with STAT3 activation. Betulin reduced NK and conventional $\mathrm{T}$ cells activation by ameliorating increased CD69 surface marker on these cells (Pfarr et al. 2015; Zhang et al. 2015; Zhou et al. 2017). While betulin strongly stimulated the IL-12p70 secretion of DCs accompanied by a specific upregulation of the IL12p35 subunit mRNA expression, betulinic acid did not exhibit this effect (Pfarr et al. 2015). Yi et al. (2010) reported that betulinic acid decreased serum IgG and IgM concentrations and increased the phagocytic activity of macrophages (Yi et al. 2010).

In addition to pro-inflammatory cytokines, betulinic acid inhibited PGE2, nitric oxide production and downregulated protein expression of iNOS and COX2.Furthermore it also inhibited COX-2 and MMP-9. It increased dose-dependently heme oxygenase (HO)-1 expression, which inhibits the production of proinflammatory cytokines. Betulinic acid treatment enhanced nuclear Nrf2 levels and decreased cytoplasmic Nrf2 levels. This anti-inflamatory action was mediated by NF- $\kappa B$ signaling. It suppressed of $\mathrm{I} \kappa \mathrm{B}$ phosphorylation, p65 phosphorylation, and nuclear translocation as well as the transcription of the related

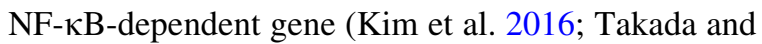
Aggarwal 2003; Yun et al. 2003). Nicotinamide adenine dinucleotide phosphate diaphorase (NADPH-d), an indirect indicator of NO synthase in the thymus and spleen. Pang et al. (2018) suggested that betulinic acid upregulated the expression of NADPH-d activity and that NO signaling may be a potential mechanism underlying betulinic acid-induced immunomodulation in the thymus and spleen (Pang et al. 2018).
Overall, betulin and betulinic acid exhibit immunomodulatory action by enhancing cellular immunity, humoral immunity, and the activity of macrophages. Notably, these compounds are modulators of Th1/Th2 cells cytokine production, suggesting that they can be used for modulation of the immune system and as anti-inflammatory agents.

Lanostane type triterpenes

\section{Ganoderic acids}

Ganoderic acids (Fig. 10) are lanostane triterpenoids isolated from Ganoderma lucidum (Curtis) Karst. (Polyporaceae), which is a medicinal mushroom that has shown to have anti-inflammatory and immunoregulatory effects (Sheng et al. 2019). More than 130 ganoderic acid and related derivatives have been isolated and identified (Radwan et al. 2011).

Many studies are conducting ganoderic acid's effects on the immune system. Ganoderic acid $\mathrm{T}$ inhibited the nuclear translocation of NF- $\mathrm{KB}$ and the<smiles>[R]C(/C(C)=C/C(C)C(=O)O)C(C)C1C[C@H](OC(C)=O)[C@]2(C)C3=CCC4C(C)(C)[C@@H](OC(C)=O)CC[C@]4(C)C3=CC[C@]12C</smiles>
$\mathrm{R}: \mathrm{H}$
Ganoderic acid Me
$\mathrm{R}: \mathrm{OCOCH}_{3}$
Ganoderic acid T

Fig. 10 Structures of some ganoderic acids 
degradation of $\mathrm{I} \kappa \mathrm{B}-\alpha$, which ultimately led to a decrease of MMP-9, iNOS, and urokinase-type plasminogen activator (Radwan et al. 2011). Ganoderic acid Me strengths the immune function by increasing the expression of Th1 cytokines (IL-2 and IFN- $\gamma$ ) and enhancing NK activity via up-regulation of expression of NF- $\kappa B$ (Wang et al. 2007; Radwan et al. 2011). Deacetyl ganoderic acid F inhibited LPS-induced NO production and iNOS expression and affected the levels of pro-inflammatory cytokines, including TNF$\alpha$ and IL-6, as well as their mRNA levels in vitro in murine microglial cell line BV-2 cells or in vivo in mouse and zebrafish models. Lupeol induced antiinflammatory action was related to the suppression of NF- $\kappa$ B activation (Sheng et al. 2019).

Indolamine 2,3-dioxygenase is a key enzyme in T-cell suppression and the induction of immune tolerance. This enzyme is preferably induced by IFN- $\gamma$. Gonaderic acid Me boosted the secretion of IFN- $\gamma$ and then upregulated the expression of indolamine 2,3-dioxygenase may be via the JAKSTAT pathway. Gonaderic acid Me contributed to indolamine 2,3-dioxygenase, enhancing Treg-mediated immunosuppression by directly inducing $\mathrm{T}$ cell apoptosis and restraining $\mathrm{CD} 8+\mathrm{T}$ cell activation (Que et al. 2014). Liu et al. (2015) isolated ganoderic acid $\mathrm{C} 1$ as the major TNF- $\alpha$ inhibitory compound in ASHMITM which is an aqueous extract of three medicinal plants -G. lucidum, Sophora flavescens Ait, and Glycyrrhiza uralensis Fischer- and clinically used in asthma patients. Ganoderic acid C1 significantly reduced TNF- $\alpha$ production by RAW 264.7 cells and PBMCs from asthma patients. Inhibition was associated with down-regulation of NF- $\kappa \mathrm{B}$ expression, and partial suppression of MAPK and AP-1 signaling pathways (Liu et al. 2015). Ganoderic acid A significantly suppressed both the constitutively activated and IL-6-induced STAT 3 phosphorylation in HepG2 cells. Inhibition of STAT3 tyrosine phosphorylation was due to suppression of JAK1 and JAK2 (Yao et al. 2012).

Overall, modulation of the NF- $\mathrm{BB}$ pathway seems to be the dominant mechanism of the immunomodulatory effect of ganoderic acids.

\section{Cucumarioside}

Cucumarosides (Fig. 11) are lanostane type triterpene oligoglycosides found in an edible sea cucumber
Cucumaria japonica. The structure consist of carbohydrate chains with five monosaccharide units linked to C-3 of aglycons, which are represented by the lanostane 18(20)-lactones, with one, two or three sulfate groups linked with sugars (Avilov et al. 1990).

Cucumariosides increased macrophage activity significantly in vivo. In contrast, they immediately inhibited leukocyte phagocytosis by human granulocytes and LPS-induced TNF- $\alpha$ production by human monocyte/macrophages in vitro. As a result of in vivo tests, a difference was found between the results of monosulfated, disulfated, and trisulfated derivatives in terms of enhancing macrophage lysosomal activity, as a result, it has been suggested that the carbohydrate chain is important in inducing the immune response (Aminin et al. 2001). In addition, Aminin et al. (2006) revealed that cumaside, a monosulfated cucumarioside with cholesterol, stimulated phagocytosis, ROS formation, IL- 6 and TNF- $\alpha$ production in lymphocytes, increased the number of antibody producing cells and supported the expression of several cell surface molecules including CD3, CD4, CD8 without proliferative activity of lymphocytes, cytotoxic activity of NK-cells and cytokine IFN $\gamma$ and IL12p70 release. An antigen carrier containing cucumariosideA2-2, cholesterol and monogalactosyldiacylglycerol showed immunostimulatory effect by affecting synthesis of IL-2, and $\gamma$-interferon (IFN- $\gamma$ ) ( $\mathrm{Li}$ et al. 2008).

As lysomal activity is one of the important markers of physiological and biochemical macrophage status, the immunomodulatory activity of monosulfated glycosides isolated from Cucumaria okhotensis was investigated by their effects on the spreading and lysosomal activity of mouse macrophages. Cucumarioside $\mathrm{A}_{2}-5$, one of the isolated monosulfated glycosides activated lysosomal activity approximately 1.5-2.5 times greater than that of control cells (Aminin et al. 2010b). Cucumarioside A2-2 was found to express immunostimulatory effect by increasing the number, spreading reaction and motility velocity of macrophages and enhancing immune cell adhesion on an extracellular matrix (Aminin et al. 2011). Membranotropic activity of the compound was also investigated by Pislyagin et al. (2012) and 0.001-0.1 $\mu \mathrm{M}$ cucumarioside $\mathrm{A}_{2}-2$ was found to stimulate intact macrophages as a rapid increase in fluorescence intensity corresponding with depolarization of cells and increases the lysosomal activity of immune cells at 
Fig. 11 Structures of some cucumarosides

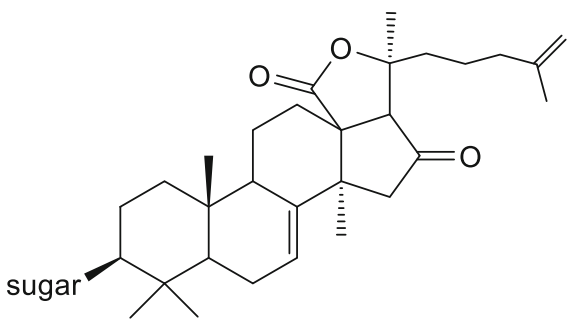

Cucumaroside $\mathrm{A}_{2}$

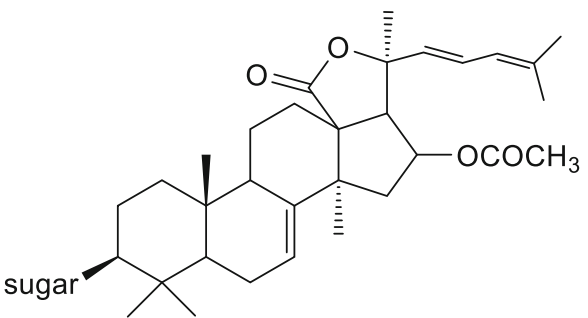

Cucumaroside I2 nanomolar concentrations, while higher concentrations were found to suppress this cellular function. The binding of cucumarioside $\mathrm{A}_{2}$-2 with cellular biomembranes triggers a series of intracellular reactions leading the immunostimulatory response of which first step is the activation of the $\mathrm{Ca}^{2+}$-signal pathway through membrane $\mathrm{Ca}^{2+}$ channels, which initiates the increase in expression of intracellular target proteins that are involved in key stages of immune cell physiology. Changes in membrane potential and transient $\left[\mathrm{Ca}^{2+}\right]_{\mathrm{i}}$ were demonstrated by single macrophage cells in response to extracellular cucumarioside $\mathrm{A}_{2}$-2 (Psilyagin et al. 2012). The intraperitoneal administration of cucumarioside $\mathrm{A}_{2}-2$ activated the cellular immunity by increasing the formation of spleen macrophage activating markers iba-1, IL-1 $\beta$, iNOs, ROS and NO with additional change of macrophage phenotype to M1 in vivo by microdissection method (Psilyagin et al. 2017). The immunomodulatory action of cucumarioside $\mathrm{A}_{2}-2$ was also demonstrated with proteomic methods. Aminin et al. (2009) stated that the mechanism of the action on mouse splenocytes includes regulation of expression of some proteins such as NSFL1, cofactor p47 and hnRNP K (down-regulated), as well as Septin2, NADH dehydrogenase [ubiquinone] iron-sulfur protein 3, and GRB2-related adaptor protein 2 (upregulated) involving into the processes of lysosome maturation, activation and lysosome merging, phagocytosis, cytoskeletal reorganization, cell adhesion, mobility and proliferation of immune cells.

Cucumarioside $\mathrm{I}_{2}$ which has disulfated branched pentaoside structure, from a sea cucumber species, Eupentacta fraudatrix, expressed immunostimulatory activity by increasing the lysosomal activity (15 $17 \%$ ) of macrophages at the doses of $1-5 \mathrm{mg} / \mathrm{mL}$ (Silchenko et al. 2013).
In a study examining the ability of cucumarioside and holotoxin to form supramolecular complexes with cholesterol or monogalactosyldiacylglycerol or phosphatidylcholine, the inclusion of pore-forming protein YompF antigen in the complex caused an increase in the diameter of tubular particles and the inclusion of "Influvac" antigens, which is also a commercial vaccine, created "cap" formation at the end of the tubules and supramolecular complex of monogalactosyldiacylglycerol, cholesterol and cucumarioside has been found to have the potential to be a carrier for bacterial and viral antigens (Mazeika et al. 2013).

In general, it is stated that cucumariosides are noted to have antiviral activity, possibly through the activation of T- and B-cell cooperation by affecting IL-2, IFN- $\gamma$, and TNF- $\alpha$ production. In addition, the aforementioned compounds regulate the expression of some proteins participating in the formation of the cellular immune response, promote proliferation and adhesion of lymphocytes, and activate the lysosomal activity of macrophages (Aminin et al. 2010a).

\section{Cycloartane-type triterpenes}

\section{Astragalosides}

The astragalosides (Fig. 12), a series of chemical compounds that have cycloartane-type saponin structure, are considered to be one of the major bioactive ingredients of Astragalus L. species (Fabaceae). There are many studies indicating broad range of pharmacological properties of these compounds, including immunomodulatory effects, as well as anti-inflammatory, anti-viral, and anti-tumor activities. In the literature, they emphasized to have both immunoregulatory and immunostimulatory effects (Qi et al. 2017). 


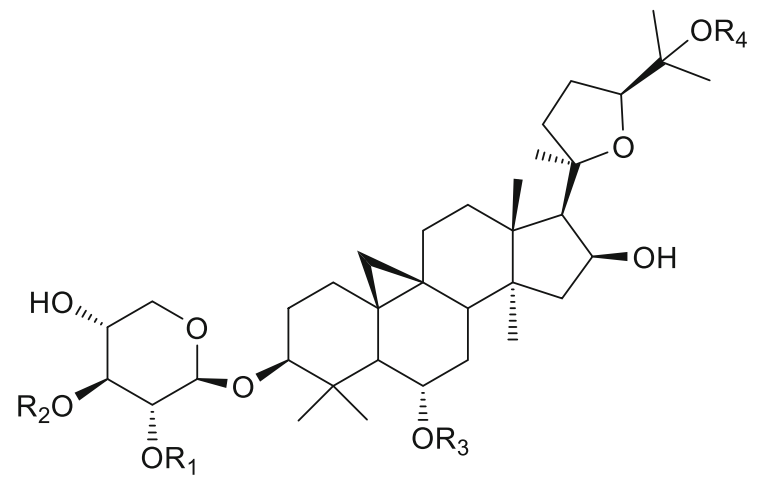

$\begin{array}{lllll} & \mathrm{R}_{1} & \mathrm{R}_{2} & \mathrm{R}_{3} & \mathrm{R}_{4} \\ \text { Astragaloside I } & \mathrm{Ac} & \mathrm{Ac} & \mathrm{Glu} & \mathrm{H} \\ \text { Astragaloside II } & \mathrm{Ac} & \mathrm{H} & \mathrm{Glu} & \mathrm{H} \\ \text { Astragaloside III } & \mathrm{Glu} & \mathrm{H} & \mathrm{H} & \mathrm{H} \\ \text { Astragaloside IV } & \mathrm{H} & \mathrm{H} & \mathrm{Glu} & \mathrm{H} \\ \text { Astragaloside VII } & \mathrm{H} & \mathrm{H} & \mathrm{H} & \mathrm{Glu}\end{array}$

Fig. 12 Structures of some astragalosides

Including astragalosides, 19 cycloartane-type saponins of Astragalus species were investigated in terms of immunostimulant effects on macrophage activation and expression of inflammatory cytokines. At low concentrations $(100 \mu \mathrm{g} / \mathrm{ml})$, none of the compounds were able to active on macrophage activation. Bedir et al. (2000) showed that astragaloside I which increased $\mathrm{NF}-\kappa \mathrm{B}$, directed luciferase expression up to $65 \%$ as compared with maximal stimulation by E. coli LPS at $10 \mu \mathrm{g} / \mathrm{ml}$. The compound also increased mRNA expression of the inflammatory cytokines IL$1 \beta$ and TNF- $\alpha$ as evaluated by reverse transcriptasepolymerase chain reaction (Bedir et al. 2000). Astragaloside I, astragaloside II, astragaloside IV, and astragaloside VII showed significant IL-2 inducing activity between $35.9 \%$ and $139.6 \%$. Among them, the activity of astragaloside VII was found as the most remarkable (Yeşilada et al. 2005). Due to the immunostimulatory capacity of astragaloside VII, its adjuvant potential on the cellular and humoral immune responses of Swiss albino mice was evaluated. Astragaloside VII significantly enhanced BSA-specific IgG, IgG1 and IgG2b antibody titers in serum and stimulated IFN- $\gamma$ production such as Freund's adjuvant, two weeks after the last immunization at doses of $120 \mu \mathrm{g}$ and $90 \mu \mathrm{g}$, respectively, as compared to the control (Nalbantsoy et al. 2011). To investigate the effects of astragaloside VII on immune response cytokines from another perspective, an in vivo study was performed using 6-8-week-old male Swiss albino mice. The results showed that astragaloside VII had a positive effect on Th1 cytokine release (IL-2 and IFN- $\gamma$ ) and suppression of Th2 cytokine production (IL-4). The compound also induced potent immunomodulatory effect in mice without inducing inflammatory cytokines and had no significant effect on inflammatory cellular targets in vitro. Immunohistochemical results demonstrated induction of both CD25 and CD69 surface receptors, justifying Th1 cytokine release. The compound did not appear to affect NF- $\mathrm{KB}$ or NAG-1 activity (Nalbantsoy et al. 2012).

Astragaloside I, astragaloside II, and astragaloside IV increased the antibody response against cancer peptide antigen MUC1 and keyhole limpet hemocyanin $(\mathrm{KLH})$ in mice when injected together with MUC1-KLH. The researchers concluded that astragaloside IV could be used as an immunological adjuvant since astragalosides II and IV were the most active compounds, whereas, astragaloside II is the most toxic one (Hong et al. 2011).

Most of the activity studies were concentrated on the astragaloside IV molecule. MTT assay was used to determine the effect of astragaloside IV on T and B lymphocyte proliferation. Astragaloside IV increased $\mathrm{T}$ and $\mathrm{B}$ lymphocyte proliferation in vivo and in vitro but inhibited the production of IL- 1 and TNF- $\alpha$ in vitro at the doses of 100-1000 nM. On the contrary, it enhanced IL-1 production at low dose $(1 \mathrm{nM})$ in vitro (Wang et al. 2002).

The effect of astragaloside IV administration at the experimental autoimmune encephalomyelitis animal model was examined by suppressing the maturation and function of DCs in mice. The maturation and the antigen presentation of LPS-stimulated bone marrow DCs in spleen of mice was inhibited by astragaloside IV. The inhibition was evidenced by decreased expressions of CD11c, CD86, CD40 and major histocompatibility complex-II. DCs treated by Astragaloside IV found to secrete less IL-6 and IL-12 and prevent the differentiation of CD $4+\mathrm{T}$ cells into Th1 and Th17 cells. It has been stated that this action may occur by inhibiting the activation of NFKB and MAPK signaling pathways (Yang et al. 2020). The same group of researchers also conducted both in vitro and in vivo studies using the same model in vivo, obtained the similar outcome. They reported that astragaloside IV suppresses the percentage of Th1 and Th17 cells, 
that are related with the inhibition of JAK/STAT and NF- $\kappa \mathrm{B}$ signaling pathways. On the other hand, in vitro experiments revealed that the molecule can regulate the differentiation of Th17 and regulatory $\mathrm{T}$ cells (Tregs) cells but not Th1 cells and additionally it induces the apoptosis of myelin oligodendrocytelycoprotein-stimulated autoreactive $\mathrm{CD} 4+\mathrm{T}$ cells probably through modulating STAT3/Bcl-2/Bax signaling pathways (Yang et al. 2019).

The anti-inflammatory potential of astragaloside IV was correlated with its NF- $\kappa \mathrm{B}$ inhibitory effect, also shown by another study. Astragaloside IV deactivates the expression of the endothelial cells E-selectin and VCAM-1, in response to inflammatory mediators (Zhang et al. 2003). Zhang and Deng (2019) investigated the effects of astragaloside IV on inflammation and immunity in rats with a periodontitis test model. They reported that, comparing with the model group, the general state of rats was improved in $40 \mathrm{mg} / \mathrm{kg}$ astragaloside IV group, while the peripheral blood $\mathrm{CD} 4+\mathrm{T}$ cell percentage and $\mathrm{CD} 4+/ \mathrm{CD} 8+$ ratio and $\mathrm{CD} 8+\mathrm{T}$ cell percentage was considerably reduced $(\mathrm{p}<0.05)$ and while the serum TNF- $\alpha$, IL$1 \beta$, IL-2 levels and serum Ig A and Ig G levels were considerably reduced $(\mathrm{p}<0.05)$. Huang et al. (2012) studied the antagonistic effects of different doses $(50 \mu \mathrm{g} / \mathrm{ml}$ and $100 \mu \mathrm{g} / \mathrm{ml})$ of astragaloside IV on the immune function of Tregs mediated by HMGB1, in vitro. The researchers analyzed the cell phenotypes of Tregs, and determined the contents of various cytokines in the cell supernatants as a result of coculture and the proliferation of $\mathrm{CD} 4{ }^{+} \mathrm{CD} 25^{-} \mathrm{T}$ cells. They showed that HMGB1 stimulation resulted in significantly down-regulation of expressions of Tregs cell phenotypes. On the other hand, it has been stated that astragaloside IV may rival the suppressive effect of HMGB1 on the immune function of Tregs in a dosedependent manner in vitro (Huang et al. 2012).

$\mathrm{Li}$ et al. (2017) investigated the effects of astragaloside IV on the immune functions of RAW264.7 cells. Compared with the control group, the concentrations of IL-1 $\beta$, TNF- $\alpha$, and NO were increased by astragaloside IV treatment. The IL-6 concentration was found to be significantly higher in the 50 and $100 \mu \mathrm{g} / \mathrm{mL}$ astragaloside IV treatment groups. The relative mRNA expression levels of IL-1 $\beta$, TNF- $\alpha$, and iNOS were significantly higher in the 50 and $100 \mu \mathrm{g} / \mathrm{mL}$ astragaloside IV treatment groups and IL6 in the $100 \mu \mathrm{g} / \mathrm{mL}$ group. Astragaloside IV markedly decreased the relative mRNA expression levels of IL4 and IL- 6 and promoted the secretion of CD40 and CD86 and increased the number of cells in the G2/M phase. Apoptosis of RAW264.7 cells was reduced and protein levels of cyclin D1, CDK4, and CDK6, p50, and p-p65 increased in a dose-dependent manner by the astragaloside IV treatment groups (Li et al. 2017).

Wan et al. (2013) analyzed the molecular mechanisms underlying the immunomodulatory acitivity of astragalosides, by focusing on CD45 protein tyrosine phosphatase (CD45 PTPase), which plays a critical role in T lymphocyte activation. Astragaloside I, II, III, and IV increased CD45-mediated para-nitrophenylphosphate/3-O-methylfluoresceinphosphate substrat hydrolysis in a concentration-dependent manner, with EC50 values in the range of 3.33 to $10.42 \mu \mathrm{g} /$ $\mathrm{mL}$. Astragaloside II significantly increased the proliferation of primary splenocytes induced by Con A, alloantigen or anti-CD3, when administered at doses of 10 and $30 \mathrm{nM}$. It also increased IL-2 and IFN- $\gamma$ secretion, upregulated the mRNA expression of IFN- $\gamma$ and T-bet in primary splenocytes, and enhanced the expression of CD25 and CD69 on primary CD4 $+\mathrm{T}$ cells upon TCR stimulation at $30 \mathrm{nM}$. Withal, the compound promoted CD45-mediated dephosphorylation of LCK (Tyr505) in primary T cells, which could be blocked by a specific CD45 PTPase inhibitor, at the dose of $100 \mathrm{nM}$. In cyclophosphamide-induced immunosuppressed mice, oral administration of astragaloside II restored the proliferation of splenic T cells and the production of IFN- $\gamma$ and IL- 2 . However, it was stated that astragaloside II did not have a clear effect on B cell proliferation (Wan et al. 2013).

Considered in general, astragaloside I has been found to be effective in increasing NF- $\kappa \mathrm{B}$-directed luciferase expression and also the mRNA expression of inflammatory cytokines, such as IL- $1 \beta$ and TNF- $\alpha$ (Yeşilada et al. 2005). Astragaloside II exhibited significant immunomodulatory effects, including a remarkable enhancement of $\mathrm{T}$ lymphocyte proliferation (Wan et al. 2013). Astragaloside activates the NF$\kappa \mathrm{B} / \mathrm{MAPK}$ signaling pathway (Li et al. 2017). Since astragaloside IV alleviates the inflammatory reaction by activating immune function of regulatory T-cells, studies on this compound have focused on diseases of inflammatory origin. Astragaloside VII was reported to show powerful immunoregulatory effects without stimulating the inflammatory cytokines in mice (Nalbantsoy et al. 2012). 
Structure-activity relationship

The triterpenoids which derived from squalene or related acyclic 30-carbon precursors can be classified as 6-6-6-5 tetracyclic, 6-6-6-6-5 pentacyclic, or 6-6-66-6 pentacyclic, but acyclic, monocyclic, bicyclic, tricyclic, and hexacyclic triterpenoids have also been isolated from natural sources. The reason for the different results of the immunomodulatory activity in the experiments on these compounds may be that they have different substitutions in their basic skeleton.

Effects of betulinic acid, oleanolic acid, and ursolic acid on T-cell proliferation were investigated. Oleanolic acid stimulated $\mathrm{T}$-cell proliferation at a low concentration $(0.5 \mu \mathrm{g} / \mathrm{mL})$ while betulinic acid and ursolic acid inhibited T-cell proliferation (with IC50 values of $50 \mu \mathrm{g} / \mathrm{mL}$ and $3.01 \mu \mathrm{g} / \mathrm{mL}$, respectively). The structures of oleanolic acid and ursolic acid differ only in the E ring. It has been stated that the different position of the methyl group in the $\mathrm{E}$ ring may be responsible for the difference observed in their activity (Choi et al. 2001). T cell proliferation inhibitory activities of betulinic acid with a five-membered E-ring and ursolic acid with a six-membered E-ring were compared. The stronger activity of ursolic acid showed that the E ring of pentacyclic triterpene was important for the inhibitory effect (Holanda Pinto et al. 2008). The immunomodulatory effect of lupeol, betulinic acid, ethyl betulinate, and lupenyl acetate was investigated by phagocyte chemiluminescence and lymphocyte proliferation assays. The presence of the esteric group at C-28 was found to play an important role in enhancing the $\mathrm{T}$-cell proliferation inhibitory effect of ethyl betulinate (Shahlaei et al. 2013).

The immunomodulatory activities of oleanolic acid, maslinic acid, erythrodiol, and uvaol compounds on cytokine production of PBMCs were compared, and it was found that erythrodiol with a fivemembered E-ring showed the most potent IL-1 $\beta$ production and IL-6 production-reducing activity at a dose of $100 \mu \mathrm{mol} / \mathrm{L}$. When compared in terms of their activities on TNF-a production, it was observed that erythrodiol did not show activity, whereas uvaol and oleanolic acid at a concentration of $100 \mu \mathrm{mol} / \mathrm{L}$ significantly inhibited TNF-a production (MarquezMartin et al. 2006). The structure of uvaol and oleanolic acid differs according to the presence of carboxyl group and methanol in C-17. It has been reported that a methanol group at $\mathrm{C}-17$, carbonyl group substitution at $\mathrm{C}-3$ in the $\mathrm{A}$ ring along a methyl group substitution at $\mathrm{C}-20$ at the $\mathrm{E}$ ring are important in terms of the inhibitory effect on pro-inflammatory cytokine production (Harun et al. 2020).

Human neutrophil elastase is important for phagocytosis activity as it aids neutrophil migration towards the infection side. The human neutrophil elastase inhibitory activities of ursolic acid, oleanolic acid, betulinic acid, and lupeol were evaluated. Substitution of the carboxyl group in C-28 may be important for the activity since ursolic acid is the molecule that most potently inhibits the production of the serine protein among others. It was confirmed by a molecular docking study that $28-\mathrm{COOH}$ and a double bond in the triterpene skeleton made it possible to increase the inhibitory activity (Feng et al. 2013).

Overall, studies suggest that the presence of an oxygenated group at C-3 as well as a carboxyl group at C-28 of the A ring may enhance immunosuppression activity on radical oxygen species production and chemotaxis of human neutrophils (Harun et al. 2020).

\section{Conclusion}

The reviewed studies indicate that triterpenes have the potential to further development as immunomodulatory agents for different purposes. Triterpenes have a multiple targeting role in immunomodulation. However, regulation of the Th1/Th2 balance seems to be the most common phenomenon. Especially, suppression of Th1 pro-inflammatory cytokines which is important to hamper the 'cytokine storm' and a range of neurodegenerative diseases related to inflammation. The high anti-inflammatory potential of triterpenes also contributes to their immunomodulatory action. Their anti-inflammatory potential not only stems from the inhibition of pro-inflammatory cytokines but is also related to a broad range of anti-inflammatory drug targets including COX-2, PGE2, MMPs, iNOS, HMGB1, ICAM-1.

Triterpenes target and ameliorate expression of various accessory proteins associated with the TLR, STAT3, NF- $\kappa$ B, MAPKs, PI3K/Akt. These proteins and pathways can be given underlying mechanisms of the immunoregulatory action of triterpenes.

In spite of many clinical trials were conducted on triterpenes related to their immunoregulatory actions, 
some of studies have several limitations. Therefore, more studies with optimal design, especially with large subject group is essential.

Most of the triterpenes mentioned in this paper are the main components of plants used in Traditional Chinese Medicine related to the immune system. We have reviewed oleanolic acid, glycyrrhizin, glycyrrhetinic acid, pristimerin, ursolic acid, boswellic acid, celastrol, lupeol, betulin, betulinic acid, ganoderic acid, cucumarioside, and astragalosides which have important immunoregulatory properties, by this study. According to current references, it seems that immunoregulatory properties of aforementioned compounds are all promising. Astragalosides are already used as immunoadjuvant agents, which make them one step further as immunoregulatory compounds.

Some triterpenes are already used in clinics as western medicine for different purposes. For example, glycyrrhizin is used for hepatitis, while glycyrrhetinic acid (enoxolone) is used for peptic ulcer treatment. Moreover, a triterpene semisynthetic derivative, bevirimat (3-O-(3', 3'-dimethylsuccinyl)-betulinic acid) is used for HIV treatment. Hence, the application potential of these compounds in the clinic is already proven. However, information on pharmacokinetics of triterpenes after administration, systemic evaluation of the bioactivities, derivatives, and metabolites products are scarce and need to be clarified. Besides, in vitro and in vivo studies with unrealistic doses should be disregarded related to immunoregulatory actions of triterpeneoids. Moreover, current promising results should be further substantiated by more properly designed clinical studies with a higher number of patients enrolled.

\section{References}

Abdin AA, Hasby EA (2014) Modulatory effect of celastrol on Th1/Th2 cytokines profile, TLR2 and CD3 + T-lymphocyte expression in a relapsing-remitting model of multiple sclerosis in rats. Eur J Pharmacol 742:102-112

Ahmad SF, Khan B, Bani S, Suri KA, Satti NK, Qazi GN (2006) Amelioration of adjuvant-induced arthritis by ursolic acid through altered Th1/Th2 cytokine production. Pharmacol Res 53:233-240

Aminin DL, Agafonova IG, Berdyshev EV, Isachenko EG, Avilov SA, Stonik VA (2001) Immunomodulatory properties of cucumariosides from the edible far-eastern holothurian Cucumaria japonica. J Med Food 4(3):127-135
Aminin DL, Pinegin BV, Pichugina LV, Zaporozhets TS, Agafonova IG, Boguslavski VM, Silchenko AS, Avilov SA, Stonik VA (2006) Immunomodulatory properties of cumaside. Int Immunopharmacol 6:1070-1082

Aminin DL, Koy C, Dmitrenok PS, Müller-Hilke B, Koczan D, Arbogast B, Sichenko AA, Kalinin VI, Avilov SA, Stonik VA, Collin PD, Thiesen H, Deinzer ML, Glocker MO (2009) Immunomodulatory effects of holothurian triterpene glycosides on mammalian splenocytes determined by mass spectrometric proteome analysis. J Proteomics 72:886-906

Aminin DL, Chaykina EL, Agafonova IG, Avilov SA, Kalinin VI, Stonik VA (2010a) Antitumor activity of the immunomodulatory lead cumaside. Int Immunopharmacol 10:648-654

Aminin DL, Silchenko AS, Avilov SA, Stepanov VG, Kalinin VI (2010b) Immunomodulatory action of monosulfated triterpene glycosides from the sea cucumber Cucumaria okhotensis: stimulation of activity of mouse peritoneal macrophages. Nat Prod Commun 5(12):1877-1880

Aminin DL, Gorpenchenko TY, Bulgakov VP, Andryjashchenko PV, Avilov SA, Kalinin VI (2011) Triterpene glycoside cucumarioside A2-2 from sea cucumber stimulates mouse immune cell adhesion, spreading, and motility. J Med Food 14(6):594-600

Ammon HP (2010) Modulation of the immune system by Boswellia serrata extracts and boswellic acids. Phytomedicine 17:862-867

Ammon HPT (2019) Boswellic extracts and 11-keto-ß-boswellic acids prevent type 1 and type 2 diabetes mellitus by suppressing the expression of proinflammatory cytokines. Phytomedicine 63:153002. https://doi.org/10.1016/j. phymed.2019.153002

Ammon HP, Mack T, Singh GB, Safayhi H (1991) Inhibition of leukotriene B4 formation in rat peritoneal neutrophils by an ethanolic extract of the gum resin exudate of Boswellia serrata. Planta Med 57:203-207

Arango Duque G, Descoteaux A (2014) Macrophage cytokines: involvement in immunity and infectious diseases. Front Immunol 5:491

Asghari E, Rashidlamir A, Hosseini SRA, Moazzami M, Samarghandian S, Farkhondeh T (2020) Synergism effects of ursolic acid supplementation on the levels of irisin, C-reactive Protein, IL-6, and TNF- $\alpha$ during high-intensity resistance training in low activity men. Cardiovasc Hematol Disord Drug Targets 20:138-144

Astry B, Venkatesha SH, Laurence A, Christensen-Quick A, Garzinodemo A, Frieman MB, O'Shea JJ, Moudgil KD (2015) Celastrol, a Chinese herbal compound, controls autoimmune inflammation by altering the balance of pathogenic and regulatory $\mathrm{T}$ cells in the target organ. Clin Immunol 157:228-238

Avilov SA, Stonik VA, Kalinovsky AI (1990) Structures of four new triterpene glycosides from the holothurian Cucumaria japonica. Chem Nat Compd 26:670-675

Badria FA, Mikhaeil BR, Maatooq GT, Amer MM (2003) Immunomodulatory triterpenoids from the oleogum resin of Boswellia carterii. Birdwood Z Naturforsch C J Biosci 58:505-516

Bailly C, Vergoten G (2020) Glycyrrhizin: An alternative drug for the treatment of COVID-19 infection and the associated 
respiratory syndrome? Pharmacol Ther 214:107618-107618. https://doi.org/10.1016/j. pharmthera.2020.107618

Bani S, Kaul A, Khan B, Ahmad SF, Suri KA, Gupta BD, Satti NK, Qazi GN (2006) Suppression of T lymphocyte activity by lupeol isolated from Crataeva religiosa. Phytother Res 20:279-287

Baram SM, Karima S, Shateri S, Tafakhori A, Fotouhi A, Lima BS, Rajaei S, Mahdavi M, Tehrani HS, Aghamollaii V, Aghamiri SH, Mansouri B, Gharahje S, Kabiri S, Hosseinizadeh M, Shahamati SZ, Alborzi AT (2019) Functional improvement and immune-inflammatory cytokines profile of ischaemic stroke patients after treatment with boswellic acids: a randomized, double-blind, placebocontrolled, pilot trial. Inflammopharmacology 27:1101-1112

Battineni JK, Koneti PK, Bakshi V, Boggula N (2018) Triterpenoids: A review. Int J Pharm Pharm Sci 3:91-96

Bedir E, Pugh N, Calis İ, Pasco D, Khan IA (2000) Including astragalosides, 19 cycloartane-type saponins of Astragalus species were investigated. Biol Pharm Bull 23(7):834-837

Bordbar N, Karimi MH, Amirghofran Z (2012) The effect of glycyrrhizin on maturation and $\mathrm{T}$ cell stimulating activity of dendritic cells. Cell Immunol 280:44-49

Cao ZY, Liu Y, Li J, Ruan Y, Yan W, Zhong S, Zhang T, Liu L, Wu R, Wang B, Wang W, Bi X, Wang Y, Su W, Jiang C (2020) Glycyrrhizic acid as an adjunctive treatment for depression through anti-inflammation: a randomized placebo-controlled clinical trial. J Affect Disord 265:247-254

Chavali SR, Francis T, Campbell JB (1987) An in vitro study of immunomodulatory effects of some saponins. Int $\mathrm{J}$ Immunopharmacol 9:675-683. https://doi.org/10.1016/ 0192-0561(87)90038-5

Chen X, Fang D, Li L, Chen L, Li Q, Gong F, Fang M (2017) Glycyrrhizin ameliorates experimental colitis through attenuating interleukin-17-producing $\mathrm{T}$ cell responses via regulating antigen-presenting cells. Immunol Res 65:666-680

Choi CY, You HJ, Jeong HG (2001) Nitric oxide and tumor necrosis factor- aproduction by oleanolic acid via nuclear factor- $\kappa \mathrm{B}$ activation in macrophages. Biochem Biophys Res Commun 288(1):49-55

Choi JK, Kim SW, Kim DS, Lee JY, Lee S, Oh HM, Ha YS, Yoo J, Park PH, Shin TY, Kwon TK, Rho MC, Kim SH (2016) Oleanolic acid acetate inhibits rheumatoid arthritis by modulating $\mathrm{T}$ cell immune responses and matrix-degrading enzymes. Toxicol Appl Pharmacol 290:1-9

Chun J, Lee C, Hwang SW, Im JP, Kim JS (2014) Ursolic acid inhibits nuclear factor- $\mathrm{\kappa B}$ signaling in intestinal epithelial cells and macrophages, and attenuates experimental colitis in mice. Life Sci 110:23-34

Córdova C, Gutiérrez B, Martínez-García C, Martín R, GallegoMuñoz P, Hernández M, Nieto ML (2014) Oleanolic acid controls allergic and inflammatory responses in experimental allergic conjunctivitis. PLoS ONE 9:e91282

Cuaz-Pérolin C, Billiet L, Bauge E, Copin C, Scott-Algara D, Genze F, Büchele B, Syrovets T, Simmet T, Rouis M (2008) Antiinflammatory and antiatherogenic effects of the NF-kappaB inhibitor acetyl-11-keto-beta-boswellic acid in LPS-challenged ApoE-/- mice. Arterioscler Thromb Vasc Biol 28:272-277
Das A, Jawed JJ, Das MC, Sandhu P, De UC, Dinda B, Akhter Y, Bhattacharjee S (2017) Antileishmanial and immunomodulatory activity of lupeol a triterpene compound isolated from Sterculia villosa. Int J Antimicrob Agents 50(4):512-522

Ding QH, Cheng Y, Chen WP, Zhong HM, Wang XH (2013) Celastrol, an inhibitor of heat shock protein $90 \beta$ potently suppresses the expression of matrix metalloproteinases, inducible nitric oxide synthase and cyclooxygenase- 2 in primary human osteoarthritic chondrocytes. Eur J Pharmacol 708:1-7

Dirsch VM, Kiemer AK, Wagner H, Vollmar AM (1997) The triterpenoid quinonemethide pristimerin inhibits induction of inducible nitric oxide synthase in murine macrophages. Eur J Pharmacol 336(2-3):211-217

Ebrahimnezhad S, Amirghofran Z, Karimi MH (2016) Decline in immunological responses mediated by dendritic cells in mice treated with $18 \alpha$-glycyrrhetinic acid. Immunol Invest 45:191-204

Feng L, Liu X, Zhu W, Guo F, Wu YC, Wang R, Chen K, Huang C, Li Y (2013) Inhibition of human neutrophil elastase by pentacyclic triterpenes. Publ Library Sci 8(12):1-11

Fu XX, Du LL, Zhao N, Dong Q, Liao YH, Du YM (2013) 18 $\beta$ Glycyrrhetinic acid potently inhibits Kv1.3 potassium channels and $\mathrm{T}$ cell activation in human Jurkat $\mathrm{T}$ cells. J Ethnopharmacol 148:647-654

Gariuc L, Sandul A, Rusu D, Passali D, Bellussi LM, Damiani V, Ciprandi G (2020) A comparison between mometasone furoate nasal spray and intranasal glycyrrhetic acid in patients with allergic rhinitis: a preliminary study in clinical practice. Acta Biomed 91:65-72

Gayathri B, Manjula N, Vinaykumar KS, Lakshmi BS, Balakrishnan A (2007) Pure compound from Boswellia serrata extract exhibits anti-inflammatory property in human PBMCs and mouse macrophages through inhibition of TNF $\alpha$, IL-1 $\beta$, NO and MAP kinases. Int Immunopharmacol 7:473-482

Ghannadian M, Akhavan A, Abdalla OM, Ayatollahi AM, Mohammadi-Kamalabadi M, Ghazanfari H (2013) Triterpenes from Euphorbia spinidens with immunomodulatory activity. Res Pharm Sci 8:205-210

Ghiulai R, Roşca OJ, Antal DS, Mioc M, Mioc A, Racoviceanu R, Macaşoi I, Olariu T, Dehelean C, Cretu OM, Voicu M, Şoica C (2020) Tetracyclic and pentacyclic triterpenes with high therapeutic efficiency in wound healing approaches. Molecules 25:5557

Graebin CS (2017) The pharmacological activities of glycyrrhizinic acid ("glycyrrhizin") and glycyrrhetinic acid. In: Merillon J-M, Ramawat KG (eds) Sweeteners: pharmacology, biotechnology, and applications. Springer, Cham

Gulati K, Guhathakurta S, Joshi J, Rai N, Ray A (2016) Cytokines and their role in health and disease: a brief overview. MOJ Immunol 4:00121

Han S, Sun L, He F, Che H (2017) Anti-allergic activity of glycyrrhizic acid on IgE-mediated allergic reaction by regulation of allergy-related immune cells. Sci Rep 7:7222. https://doi.org/10.1038/s41598-017-07833-1

Harun NK, Septama AW, Ahmad WANW, Suppian R (2020) Immunomodulatory effects and structure-activity 
relationship of botanical pentacyclic triterpenes: a review. Chin Herb Med 12:118-124

Holanda Pinto SA, Pinto LMS, Cunha GMA, Chaves MH, Santos FA, Rao VS (2008) Anti-inflammatory effect of $\alpha$, $\beta$-amyrin, a pentacyclic triter- pene from Protium heptaphyllum in rat model of acute periodontitis. Inflammopharmacology 16(1):48-52

Honda H, Nagai Y, Matsunaga T, Saitoh S, Akashi-Takamura S, Hayashi H, Fujii I, Miyake K, Muraguchi A, Takatsu K (2012) Glycyrrhizin and isoliquiritigenin suppress the LPS sensor toll-like receptor 4/MD-2 complex signaling in a different manner. J Leukoc Biol 91(6):967-976

Hong F, Xiao W, Ragupathi G, Lau CBS, Leung PC, Yeung KS, George C, Cassileth B, Kennelly E, Livingston PO (2011) The known immunologically active components of Astragalus account for only a small proportion of the immunological adjuvant activity when combined with conjugate vaccines. Planta Med 77(8):817-824

Hordyjewska A, Ostapiuk A, Horecka A, Kurzepa J (2019) Betulin and betulinic acid: triterpenoids derivatives with a powerful biological potential. Phytochem Rev 18:929-951

Hou W, Liu B, Xu H (2020) Celastrol: progresses in structuremodifications, structure-activity relationships, pharmacology and toxicology. Eur J Med Chem 189:112081

Hua H, Liang Z, Li W, Meng Y, Li X, Zhang Z, Lu C, Meng J, Shan F (2012) Phenotypic and functional maturation of murine dendritic cells (DCs) induced by purified glycyrrhizin (GL). Int Immunopharmacol 12:518-525

Huang L, Yao Y, Li J, Zhang S, Li W, Dong N, Yu Y, Sheng Z (2012) The effect of Astragaloside IV on immune function of regulatory $\mathrm{T}$ cell mediated by high mobility group box 1 protein in vitro. Fitoterapia 83:1514-1522

Hussain H, Green IR, Ali I, Khan IA, Ali Z, Al-Sadi AM, Ahmed I (2017) Ursolic acid derivatives for pharmaceutical use: a patent review (2012-2016). Expert Opin Ther Pat 27:1061-1072

Hwang YJ, Song J, Kim HR, Hwang KA (2014) Oleanolic acid regulates NF- $\kappa \mathrm{B}$ signaling by suppressing MafK expression in RAW 264.7 cells. BMB Rep 47:524-529

Jang SM, Yee ST, Choi J, Choi MS, Do GM, Jeon SM, Yeo J, Kim MJ, Seo KI, Lee MK (2009) Ursolic acid enhances the cellular immune system and pancreatic beta-cell function in streptozotocin-induced diabetic mice fed a high-fat diet. Int Immunopharmacol 9:113-119

Jang SE, Jeong JJ, Hyam SR, Han MJ, Kim DH (2014) Ursolic acid isolated from the seed of Cornus officinalis ameliorates colitis in mice by inhibiting the binding of lipopolysaccharide to Toll-like receptor 4 on macrophages. J Agric Food Chem 62:9711-9721

Jantan I, Ahmad W, Bukhari SNA (2015) Plant-derived immunomodulators: an insight on their preclinical evaluation and clinical trials. Front Plant Sci 6:655

Jehangir A, Shahzad M, Shahid K, Waheed A, Ayub F (2019) Zinc and iron complexes of oleanolic acid, (OA) attenuate allergic airway inflammation in rats. Inflammopharmacology 27:1179-1192

Jin Y, Wang Y, Zhao D, Ma S, Lu J, Shuang G (2016) Pristimerin attenuates ovalbumin-induced allergic airway inflammation in mice. Immunopharmacol Immunotoxicol 38(3):221-227
Ju SM, Youn GS, Cho YS, Choi SY, Park J (2015) Celastrol ameliorates cytokine toxicity and pro-inflammatory immune responses by suppressing NF- $\mathrm{KB}$ activation in RINm5F beta cells. BMB Rep 48:172-177

Jung HW, Chung YS, Kim YS, Park YK (2007) Celastrol inhibits production of nitric oxide and proinflammatory cytokines through MAPK signal transduction and NFkappaB in LPS-stimulated BV-2 microglial cells. Exp Mol Med 39:715-721

Kang SC, Lim SY, Song Y (2013) Lupeol is one of active components in the extract of Chrysanthemum indicum Linne that inhibits LMP1-induced NF- $\mathrm{BB}$ activation. PLoS ONE 8(11):e82688. https://doi.org/10.1371/journal.pone. 0082688

Kang YM, Lee M, An HJ (2021) Oleanolic acid protects against mast cell-mediated allergic responses by suppressing Akt/ NF- $\kappa$ B and STAT1 activation. Phytomedicine 80:153340

Kapil A, Moza N (1992) Anticomplementary activity of boswellic acids - an inhibitor of $\mathrm{C}_{3}$-convertase of the classical complement pathway. Int $\mathrm{J}$ Immunopharmacol 14:1139-1143

Karra AG, Tziortziou M, Kylindri P, Georgatza D, Gorgogietas VA, Makiou A, Krokida A, Tsialtas I, Kalousi FD, Papadopoulos GE, Papadopoulou KK, Psarra AG (2020) Boswellic acids and their derivatives as potent regulators of glucocorticoid receptor actions. Arch Biochem Biophys 695:108656. https://doi.org/10.1016/j.abb.2020.108656

Kaur G, Chauhan K, Kaur S (2019) Lupeol induces immunity and protective efficacy in a murine model against visceral leishmaniasis. Parasitology 146(11):1440-1450

Kawai T, Akira S (2007) Signaling to NF-kappaB by Toll-like receptors. Trends Mol Med 13:460-469

Kim HS, Sung HY, Kim MS, Kim JL, Kang MK, Gong JH, Park HS, Kang YH (2013a) Oleanolic acid suppresses resistin induction in adipocytes by modulating Tyk-STAT signaling. Nutr Res 33:144-153

Kim J, Joo I, Kim H, Han Y (2013b) 18ß-glycyrrhetinic acid induces immunological adjuvant activity of Th1 against Candida albicans surface mannan extract. Phytomedicine 20:951-955

Kim SH, Hong JH, Lee YC (2013c) Ursolic acid, a potential PPAR $\gamma$ agonist, suppresses ovalbumin-induced airway inflammation and Penh by down-regulating IL-5, IL-13, and IL-17 in a mouse model of allergic asthma. Eur J Pharmacol 701:131-143

Kim SH, Hong JH, Lee YC (2014) Oleanolic acid suppresses ovalbumin-induced airway inflammation and Th2-mediated allergic asthma by modulating the transcription factors T-bet, GATA-3, ROR $\gamma \mathrm{t}$ and Foxp3 in asthmatic mice. Int Immunopharmacol 18:311-324

Kim KS, Lee DS, Kim DC, Yoon CS, Ko W, Oh H, Kim YC (2016) Anti-inflammatory effects and mechanisms of action of coussaric and betulinic acids isolated from Diospyros kaki in lipopolysaccharide-stimulated RAW 264.7 macrophages. Molecules 21(9):1206. https://doi.org/ 10.3390/molecules21091206

Kim S, Heo S, Park S, Youn H (2019) Pristimerin inhibits inducible nitric oxide synthase expression induced by TLR agonists. Biomed Sci Lett 25(1):60-65

Kim M, Lee S, Lim H, Lee J, Park JY, Kwon HJ, Lee IC, Ryu YB, Kim J, Shin T, Ahn G, Rho MC, Jung K (2020) 
Oleanolic acid acetate alleviates symptoms of experimental autoimmune encephalomyelitis in mice by regulating Toll-Like Receptor 2 signaling. Front Pharmacol 11:556391

Lee JY, Lee BH, Kim ND, Lee JY (2015) Celastrol blocks binding of lipopolysaccharides to a Toll-like receptor4/ myeloid differentiation factor 2 complex in a thiol-dependent manner. J Ethnopharmacol 172:254-260

Lee C, Lee JW, Seo JY, Hwang SW, Im JP, Kim JS (2016) Lupeol inhibits LPS-induced NF-kappa B signaling in intestinal epithelial cells and macrophages, and attenuates acute and chronic murine colitis. Life Sci 146:100-108

Li IA, Popov AM, Tsybulskii AV, Sanina NM, Kostetskii E, Novikova OD, Portniagina O, Mazeika AV (2008) Immunostimulatory characteristics of a novel adjuvant on the basis of cucumarioside $\mathrm{A}_{2-2}$ and monogalactosyldiacylgycerol. Appl Biochem Microbiol 44(6):629-634

Li X-L, Zhou A-G, Zhang L, Chen W-J (2011) Antioxidant status and immune activity of glycyrrhizin in allergic rhinitis mice. Int J Mol Sci 12:905-916

Li Y, Meng T, Hao N, Tao H, Zou S, Li M, Ming P, Ding H, Dong J, Feng S, Li J, Wang X, Wu J (2017) Immune regulation mechanism of Astragaloside IV on RAW264.7 cells through activating the NF- $\mathrm{BB} / \mathrm{MAPK}$ signaling pathway. Int Immunopharmacol 49:38-49

Li J, Shi J, Sun Y, Zheng F (2018) Glycyrrhizin, a potential drug for autoimmune encephalomyelitis by inhibiting highmobility group box 1. DNA Cell Biol 37:941-946

Lim HJ, Jang HJ, Kim MH, Lee S, Lee SW, Lee SJ, Rho MC (2019) Oleanolic acid acetate exerts anti-inflammatory activity via IKK $\alpha / \beta$ suppression in TLR3-mediated NF- $\kappa B$ activation. Molecules 24:4002

Liu Z, Zhong JY, Gao EN, Yang H (2014) Effects of glycyrrhizin acid and licorice flavonoids on LPS-induced cytokines expression in macrophage. Zhongguo Zhong Yao Za Zhi 39:3841-3845

Liu C, Yang N, Song Y, Wang L, Zi J, Zhang S, Dunkin D, Busse P, Weir D, Tversky J, Miller RL, Goldfarb J, Zhan J, Li X (2015) Ganoderic acid C1 isolated from the antiasthma formula, ASHMITM suppresses TNF- $\alpha$ production by mouse macrophages and peripheral blood mononuclear cells from asthma patients. Int Immunopharmacol 27(2):224-231

Liu Y, Gao X, Deeb D, Zhang Y, Shaw J, Gautam SC (2016) Anticancer agent pristimerin inhibits IL-2 induced activation of T lymphocytes. J Exp Ther Oncol 11:181-188

Liu T, Ma H, Shi W, Duan J, Wang Y, Zhang C, Li C, Lin J, Li S, Lv J, Lin L (2017) Inhibition of STAT3 signaling pathway by ursolic acid suppresses growth of hepatocellular carcinoma. Int J Oncol 51:555-562

Marquez-Martin A, La Puerta RD, Fernandez-Arche A, RuizGutierrez V, Yaqoob P (2006) Modulation of cytokine secretion by pentacyclic triterpenes from olive pomace oil in human mononuclear cells. Cytokine 36(5-6):211-217

Martín R, Hernández M, Córdova C, Nieto ML (2012) Natural triterpenes modulate immune-inflammatory markers of experimental autoimmune encephalomyelitis: therapeutic implications for multiple sclerosis. $\mathrm{Br} \mathrm{J}$ Pharmacol 166:1708-1723

Martín R, Cordova C, San Román JA, Gutierrez B, Cachofeiro V, Nieto ML (2014) Oleanolic acid modulates the immune- inflammatory response in mice with experimental autoimmune myocarditis and protects from cardiac injury. J Mol Cell Cardiol 72:250-262

Mashitoh AR, Yeap SK, Ali AM, Faujan A, Suhaimi M, Ng MK, Lam HY, Alitheen NB (2012) Immunomodulatory effects of betulinic acid isolation from the bark of Melaleuca cajuputi. Pertanika J Trop Agric Sci 35(2):293-305

Matsui S, Sonoda Y, Sekiya T, Aizu-Yokota E, Kasahara T (2006) Glycyrrhizin derivative inhibits eotaxin 1 production via STAT6 in human lung fibroblasts. Int Immunopharmacol 6:369-375

Maurya A, Khan F, Bawankule DU, Yadav DK, Srivastava SK (2012) QSAR, docking and in vivo studies for immunomodulatory activity of isolated triterpenoids from Eucalyptus tereticornis and Gentiana kurroo. Eur J Pharm Sci 47:152-161

Mazeika AN, Kostetskii E, Sanina NM, Popov AM, Kalinin VI, Li IA (2013) Elaboration of immune stimulating lipid saponin subunit antigen carrier based on glycolipid monogalactosyldiacylglycerol from sea macrophytes and triterpene glycosides from Cucumaria japonica. Biofizika 58(5):786-795

McComb S, Thiriot A, Akache B, Krishnan L, Stark F (2019) In: Fulton K, Twine S (eds) Immunoproteomics. Methods in molecular biology. Humana, New York.

Michaelis M, Geiler J, Naczk P, Sithisarn P, Ogbomo H, Altenbrandt B, Leutz A, Doerr HW, Cinatl J (2010) Glycyrrhizin inhibits highly pathogenic H5N1 influenza A virus-induced pro-inflammatory cytokine and chemokine expression in human macrophages. Med Microbiol Immunol 199:291-297. https://doi.org/10.1007/s00430010-0155-0

Mohamed SIA, Jantan I, Haque A (2017) Naturally occurring immunomodulators with antitumor activity: An insight on their mechanisms of action. Int Immunopharmacol 50:291-304

Nalbantsoy A, Nesil T, Erden S, Çalıs İ, Bedir E (2011) Adjuvant effects of Astragalus saponins Macrophyllosaponin B and Astragaloside VII. J Ethnopharmacol 134(3):897-903

Nalbantsoy A, Nesil T, Yılmaz-Dilsiz Ö, Aksu G, Khan S, Bedir E (2012) Evaluation of the immunomodulatory properties in mice and in vitro anti-inflammatory activity of cycloartane type saponins from Astragalus species. J Ethnopharmacol 139(2):574-581

Napetschnig J, Wu H (2013) Molecular basis of NF-кB signaling. Annu Rev Biophys 42:443-468

O'Shea JJ, Plenge R (2012) JAK and STAT signaling molecules in immunoregulation and immune-mediated disease. Immunity 36:542-550

Pang KL, Vijayaraghavan K, Al Sayed B, Seyed MA (2018) Betulinic acid-induced expression of nicotinamide adenine dinucleotide phosphate-diaphorase in the immune organs of mice: A possible role of nitric oxide in immunomodulation. Mol Med Rep 17:3035-3041

Peng LN, Li L, Qiu Y, Miao J, Gao X, Zhou Y, Shi Z, Xu Y, Shao D, Wei J, Ma Z (2011) Glycyrrhetinic acid extracted from Glycyrrhiza uralensis Fisch. induces the expression of Toll-like receptor 4 in Ana-1 murine macrophages. J Asian Nat Prod Res 13:942-950

Pfarr K, Danciu C, Arlt O, Neske C, Dehelean C, Pfeilschifter JM, Radeke HH (2015) Simultaneous and dose dependent 
melanoma cytotoxic and immune stimulatory activity of betulin. PLoS ONE 10:e0118802. https://doi.org/10.1371/ journal.pone.0118802

Pislyagin EA, Manzhulo IV, Gorpenchenko TY, Dmitrenok PS, Avilov SA, Silchenko AS, Wang Y, Aminin DL (2017) Cucumarioside A2-2 causes macrophage activation in mouse spleen. Mar Drugs 15:341. https://doi.org/10.3390/ md15110341

Pratap UP, Anand K, Yasmine F, Hima L, Priyanka HP, Thyagarajan S (2016) Phytochemicals in Morinda citrifolia fruit selectively modulate age-associated immunity and antioxidant enzyme activities through ERK pathway in splenic lymphocytes of male F344 rats. J Recept Signal Transduct Res 36:139-151

Psilyagin EA, Gladkikh RV, Kapustina II, Kim NY, Shevchenko VP, Nagaev IY, Avilov SA, Aminin DL (2012) Interaction of holothurian triterpene glycoside with biomembranes of Mouse immune cells. Int Immunopharmacol 14:1-8

Pungle P, Banavalikar M, Suthar A, Biyani M, Mengi S (2003) Immunomodulatory activity of boswellic acids of Boswellia serrata. Roxb Indian J Exp Biol 41:1460-1462

Qi Y, Gao F, Hou L, Wan C (2017) Anti-inflammatory and immunostimulatory activities of astragalosides. Am J Chin Med 45(6):1-11

Que Z, Zou F, Zhang A, Zheng Y, Bi L, Zhong J, Tian J, Liu J (2014) Ganoderic acid Me induces the apoptosis of competent $\mathrm{T}$ cells and increases the proportion of Treg cells through enhancing the expression and activation of indoleamine 2,3-dioxygenase in mouse lewis lung cancer cells. Int Immunopharmacol 23:192-204

Radwan FY, Perez JM, Haque A (2011) Apoptotic and immune restoration effects of ganoderic acids define a new prospective for complementary treatment of cancer. J Clin Cell Immunol 3:4

Rajendran P, Li F, Shanmugam MK, Kannaiyan R, Goh JN, Wong KF, Wang W, Khin E, Tergaonkar V, Kumar AP, Luk JM, Sethi G (2012) Celastrol suppresses growth and induces apoptosis of human hepatocellular carcinoma through the modulation of STAT3/JAK2 signaling cascade in vitro and in vivo. Cancer Prev Res (phila) 5:631-643

Ramírez-Rodríguez AM, González-Ortiz M, Martínez-Abundis E, Acuña Ortega N (2017) Effect of ursolic acid on metabolic syndrome, insulin sensitivity, and inflammation. J Med Food 20:882-886

Raphael TJ, Kuttan G (2003) Effect of naturally occurring triterpenoids glycyrrhizic acid, ursolic acid, oleanolic acid and nomilin on the immune system. Phytomedicine 10:483-489

Raphael TJ, Kuttan G (2008) Effect of naturally occurring triterpenoids ursolic acid and glycyrrhizic acid on the cellmediated immune responses of metastatic tumor-bearing animals. Immunopharmacol Immunotoxicol 30:243-255

Ríos JL (2010) Effects of triterpenes on the immune system. J Ethnopharmacol 128(1):1-14

Roy NK, Parama D, Banik K, Bordoloi D, Devi AK, Thakur KK, Padmavathi G, Shakibaei M, Fan L, Sethi G, Kunnumakkara AB (2019) An update on pharmacological potential of boswellic acids against chronic diseases. Int $\mathrm{J}$ Mol Sci 20:4101. https://doi.org/10.3390/ijms20174101
Schröfelbauer B, Raffetseder J, Hauner M, Wolkerstorfer A, Ernst W, Szolar OH (2009) Glycyrrhizin, the main active compound in liquorice, attenuates pro-inflammatory responses by interfering with membrane-dependent receptor signalling. Biochem J 421:473-482

Sen A (2020) Prophylactic and therapeutic roles of oleanolic acid and its derivatives in several diseases. World J Clin Cases 8:1767-1792

Sengupta K, Golakoti T, Marasetti Ak, Tummala T, Ravada Sr, Krishnaraju Av, Raychaudhuri Sp (2009) Inhibition of Tnf $\alpha$ production and blocking of mitogen-activated protein kinase/Nf $\mathrm{bb}$ activation in lipopolysaccharide-induced Thp-1 human monocytes by 3-O-acetyl-11-keto-B-boswellic acid. J Food Lipids 16:325-344

Shahlaei M, Ghanadian SM, Ayatollahi AM, Mesaik MA, Abdalla OM, Af-sharypour S, Rabbani M (2013) Molecular modeling, structure activity relationship and immunomodulatory properties of some lupeol derivatives. Med Chem Res 22(4):1795-1803

Shantilal S, Vaghela JS, Sisodia SS (2018) review on immunomodulation and immunomodulatory activity of some medicinal plant. EJBPS 5(8):163-174

Sharma ML, Kaul A, Khajuria A, Singh S, Singh GB (1996) Immunomodulatory activity of boswellic acids (pentacyclic triterpene acids) from Boswellia serrata. Phytother Res 10:107-112

Sharma S, Gupta S, Khajuria V, Bhagat A, Ahmed Z, Shah BA (2016) Analogues of boswellic acids as inhibitors of proinflammatory cytokines TNF- $\alpha$ and IL-6. Bioorg Med Chem Lett 26:695-698

Sheng F, Zhang L, Wang S, Yang L, Li P (2019) Deacetyl ganoderic acid $\mathrm{F}$ inhibits LPS-induced neural inflammation via NF- $\kappa \mathrm{B}$ pathway both in vitro and in vivo. Nutrients 12:85-98

Shishodia S, Majumdar S, Banerjee S, Aggarwal BB (2003) Ursolic acid inhibits nuclear factor-kappaB activation induced by carcinogenic agents through suppression of IkappaBalpha kinase and p65 phosphorylation: correlation with down-regulation of cyclooxygenase 2 , matrix metalloproteinase 9, and cyclin D1. Cancer Res 63:4375-4383

Shokryazdan P, Faseleh Jahromi M, Navidshad B, Liang JB (2017) Effects of prebiotics on immune system and cytokine expression. Med Microbiol Immunol 206:1-9

Siddique HR, Saleem M (2011) Beneficial health effects of lupeol triterpene: A review of preclinical studies. Life Sci 88:285-293

Silchenko AS, Kalinovsky AI, Avilov SA, Andryjaschenko PV, Dmitrenok PS, Menchinskaya ES, Aminin DL, Kalinin VI (2013) Structure of cucumarioside I2 from the sea cucumber Eupentacta fraudatrix (Djakonov et Baranova) and cytotoxic and immunostimulatory activities of this saponin and relative compounds. Nat Prod Res 27(19):1776-1783

Songu M, Katılmış H (2012) Immune system and protection from infections. J Med Updates 2(1):31-42

Stürner KH, Verse N, Yousef S, Martin R, Sospedra M (2014) Boswellic acids reduce Th17 differentiation via blockade of IL-1 $\beta$-mediated IRAK1 signaling. Eur J Immunol 44:1200-1212

Syrovets T, Büchele B, Krauss C, Laumonnier Y, Simmet T (2005) Acetyl-boswellic acids inhibit lipopolysaccharide- 
mediated TNF-alpha induction in monocytes by direct interaction with IkappaB kinases. J Immunol 174:498-506

Takada Y, Aggarwal BB (2003) Betulinic acid suppresses carcinogen-induced NF- $\kappa \mathrm{B}$ activation through inhibition of $\mathrm{I} \kappa \mathrm{B} \alpha$ kinase and $\mathrm{p} 65$ phosphorylation: abrogation of cyclooxygenase-2 and matrix metalloprotease-9. J Immunsol 171:3278-3286

Tian X, Liu Y, Liu X, Gao S, Sun X (2019) Glycyrrhizic acid ammonium salt alleviates Concanavalin A-induced immunological liver injury in mice through the regulation of the balance of immune cells and the inhibition of hepatocyte apoptosis. Biomed Pharmacother 120:109481

Tong L, Nanjundaiah SM, Venkatesha SH, Astry B, Yu H, Moudgil KD (2014) Pristimerin, a naturally occurring triterpenoid, protects against autoimmune arthritis by modulating the cellular and soluble immune mediators of inflammation and tissue damage. Clin Immunol 155:220-230

Ukil A, Kar S, Srivastav S, Ghosh K, Das PK (2011) Curative effect of $18 \beta$-glycyrrhetinic acid in experimental visceral leishmaniasis depends on phosphatase-dependent modulation of cellular MAP kinases. PLoS ONE 6:e29062. https://doi.org/10.1371/journal.pone.0029062

Vasconcelos JF, Teixeira MM, Barbosa-Filho JM, Lucio ASSC, Almeida JRgs, de Queiroz LP, Ribeiro-Dos-Santos R, Soares MBP (2008) The triterpenoid lupeol attenuates allergic airway inflammation in a murine model. Int Immunopharmacol 8: 1216-1221

Wahab S, Hussain A (2013) Cytokines as targets for immunomodulation. Int J Pharm Pharm Sci 5:60-64

Wahdaningsih S, Wahyuono S, Riyanto S, Murwanti R (2020) Terpenoid-lupeol of red dragon fruit (Hylocereus polyrhizus) and its immunomodulatory activity. Pak J Pharm Sci 33(2):505-510

Wan C, Gao L, Hou L, Yang X, He P, Yang Y, Tang W, Yue J, Li J, Zuo J (2013) Astragaloside II triggers T cell activation through regulation of CD45 protein tyrosine phosphatase activity. Acta Pharmacol Sin 34:522-530

Wang Y, Yu L, Chun-Qing S, Zhi-Bi H (2002) Effect of astragaloside IV on T, B lymphocyte proliferation and peritoneal macrophage function in mice. Acta Pharmacol Sin 23(3):263-266

Wang G, Zhao J, Liu J, Huang Y, Zhong J, Tang W (2007) Enhancement of IL-2 and IFN- $\gamma$ expression and NK cells activity involved in the anti-tumor effect of ganoderic acid Me in vivo. Int Immunopharmacol 7:864-870

Wang P, Li Q, Li K, Zhang X, Han Z, Wang J, Gao D, Li J (2012) Betulinic acid exerts immunoregulation and antitumor effect on cervical carcinoma (U14) tumor-bearing mice. Pharmazie 67:733-739

Wang HL, Li Y, Niu Y, Zheng J, Wu J, Shi G, Ma L, Niu Y, Sun T, Yu J (2015a) Observing anti-inflammatory and antinociceptive activities of glycyrrhizin through regulating COX-2 and pro-inflammatory cytokines expressions in mice. Inflammation 38:2269-2278

Wang Y, Cao L, Xu LM, Cao FF, Peng B, Zhang X, Shen YF, Uzan G, Zhang DH (2015b) Celastrol ameliorates EAE induction by suppressing pathogenic $\mathrm{T}$ cell responses in the peripheral and central nervous systems. J Neuroimmune Pharmacol 10:506-516
Wang MX, Zhao J, Meng Y, Di T, Xu X, Xie X, Lin Y, Zhang L, Wang N, Li P, Wang Y (2018) Acetyl-11-keto- $\beta$-boswellic acid inhibits the secretion of cytokines by dendritic cells via the TLR7/8 pathway in an imiquimod-induced psoriasis mouse model and in vitro. Life Sci 207:90-104

Xu T, Wang X, Zhong B, Nurieva RI, Ding S, Dong C (2011) Ursolic acid suppresses interleukin-17 (IL-17) production by selectively antagonizing the function of RORgamma $t$ protein. J Biol Chem 286:22707-22710

Xu H, Zhang M, Li XL, Li H, Yue LT, Zhang XX, Wang CC, Wang S, Duan RS (2015) Low and high doses of ursolic acid ameliorate experimental autoimmune myasthenia gravis through different pathways. J Neuroimmunol 281:61-67

Yang L, Xing F, Han X, Li Q, Wu H, Shi H, Wang Z, Huang F (2019) Astragaloside IV regulates differentiation and induces apoptosis of activated CD4 $+\mathrm{T}$ cells in the pathogenesis of experimental autoimmune encephalomyelitis. Toxicol Appl Pharmacol 362(1):105-115

Yang L, Han X, Yuan J, Xing F, Hu Z, Huang F, Wu H, Shi H, Zhang T, Wu X (2020) Early astragaloside IV administration attenuates experimental autoimmune encephalomyelitis in mice by suppressing the maturation and function of dendritic cells. Life Sci 249:117448

Yao X, Li G, Xu H, Lü C (2012) Inhibition of the JAK-STAT3 signaling pathway by ganoderic acid a enhances chemosensitivity of HepG2 cells to cisplatin. Planta Med 78:1740-1748

Yeşilada E, Bedir E, Çalış İ, Takaishi Y, Ohmoto Y (2005) Effects of triterpene saponins from Astragalus species on in vitro cytokine release. J Ethnopharmacol 96:71-77

Yi JE, Obminska-Mrukowicz B, Yuan LY, Yuan H (2010) Immunomodulatory effects of betulinic acid from the bark of white birch on mice. J Vet Sci 11:305-313

You HJ, Choi CY, Kim JY, Park SJ, Hahm KS, Jeong HG (2001) Ursolic acid enhances nitric oxide and tumor necrosis factor-alpha production via nuclear factor-kappaB activation in the resting macrophages. FEBS Lett 509:156-160

Yu JJ, Zhang CS, Coyle ME, Du Y, Zhang AL, Guo X, Xue CC, Lu C (2017) Compound glycyrrhizin plus conventional therapy for psoriasis vulgaris: a systematic review and meta-analysis of randomized controlled trials. Curr Med Res Opin 33:279-287

Yun Y, Han S, Park E, Yim D, Lee S, Lee C, Cho K, Kim K (2003) Immunomodulatory activity of betulinic acid by producing pro-inflammatory cytokines and activation of macrophages. Arch Pharm Res 26:1087-1095

Zdzisińska B, Rzeski W, Paduch R, Szuster-Ciesielska A, Kaczor J, Wejksza K, Kandefer-Szerszeń M (2003) Differential effect of betulin and betulinic acid on cytokine production in human whole blood cell cultures. Pol J Pharmacol 55:235-238

Zhang L, Deng S (2019) Effects of astragaloside IV on inflammation and immunity in rats with experimental periodontitis. Braz Oral Res 33(e032):1-8

Zhang W, Hufnagl P, Binder BR, Wojta J (2003) Antiinflammatory activity of astragaloside IV is mediated by inhibition of NF-qB activation and adhesion molecule expression. Thromb Haemost 90(5):904-914 
Zhang SY, Zhao QF, Fang NN, Yu JG (2015) Betulin inhibits pro-inflammatory cytokines expression through activation STAT3 signaling pathway in human cardiac cells. Eur Rev Med Pharmacol Sci 19:455-460

Zhang J, Shan J, Chen X, Li S, Long D, Li Y (2018) Celastrol mediates Th17 and Treg cell generation via metabolic signaling. Biochem Biophys Res Commun 497:883-889

Zhao X, Liu J, Hu Y, Fan Y, Wang D, Yuan J, Xu L, Cui L, Jing Z (2012) Optimization on condition of glycyrrhetinic acid liposome by RSM and the research of its immunological activity. Int J Biol Macromol 51:299-304

Zhao J, Zheng H, Sui Z, Jing F, Quan X, Zhao W, Liu G (2019) Ursolic acid exhibits anti-inflammatory effects through blocking TLR4-MyD88 pathway mediated by autophagy. Cytokine 123:1-8

Zhou YQ, Weng XF, Dou R, Tan XS, Zhang TT, Fang JB, Wu XW (2017) Betulin from Hedyotis hedyotidea ameliorates concanavalin A-induced and T cell-mediated autoimmune hepatitis in mice. Acta Pharmacol Sin 38:201-210

Zimmermann-Klemd AM, Reinhardt JK, Nilsu T, Morath A, Falanga CM, Schamel WW, Huber R, Hamburger M, Gründemann C (2020) Boswellia carteri extract and 3-Oacetyl-alpha-boswellic acid suppress $\mathrm{T}$ cell function. Fitoterapia 146:104694. https://doi.org/10.1016/j.fitote. 2020.104694

Zong-xin C, Zhong-fang Z, Xiu-fen Z (2006) Effect of Compound Glycyrrhizin Injection on Liver Function and Cellular Immunity of Children with Infectious Mononucleosis Complicated Liver Impairment. Chin J Integr Med 12(4):268-272

Publisher's Note Springer Nature remains neutral with regard to jurisdictional claims in published maps and institutional affiliations. 